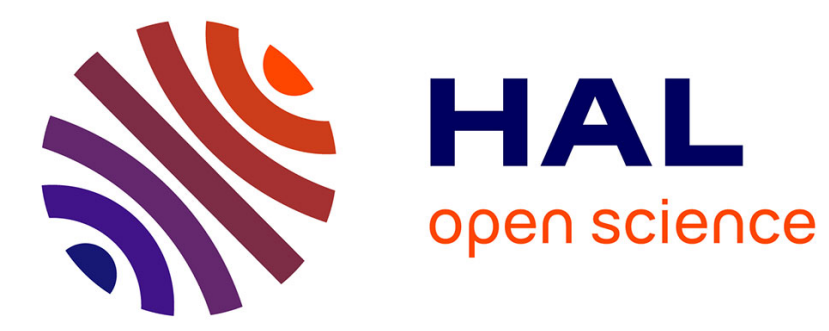

\title{
Battery/Supercapacitors Combination in Uninterruptible Power Supply (UPS)
}

Amine Lahyani, Pascal Venet, Abdessattar Guermazi, Alaeddine Troudi

\section{To cite this version:}

Amine Lahyani, Pascal Venet, Abdessattar Guermazi, Alaeddine Troudi. Battery/Supercapacitors Combination in Uninterruptible Power Supply (UPS). IEEE Transactions on Power Electronics, 2012, 28 (4), pp.1509 - 1522. 10.1109/TPEL.2012.2210736 . hal-00818704

\section{HAL Id: hal-00818704 https://hal.science/hal-00818704}

Submitted on 4 Jan 2019

HAL is a multi-disciplinary open access archive for the deposit and dissemination of scientific research documents, whether they are published or not. The documents may come from teaching and research institutions in France or abroad, or from public or private research centers.
L'archive ouverte pluridisciplinaire HAL, est destinée au dépôt et à la diffusion de documents scientifiques de niveau recherche, publiés ou non, émanant des établissements d'enseignement et de recherche français ou étrangers, des laboratoires publics ou privés. 
Preprint article A. LAHYANI, P. VENET, A. TROUDI, A. GUERMAZI

"Battery/Supercapacitors Combination in Uninterruptible Power Supply (UPS)", IEEE Transactions on

Power Electronics, Vol. 28, n 4, April. 2013, pp 1509 - 1522

\title{
Battery/Supercapacitors Combination in Uninterruptible Power Supply (UPS)
}

\author{
Amine Lahyani ${ }^{(1)}$, Pascal Venet ${ }^{(2)}$, Abdessattar Guermazi ${ }^{(3)}$ and Alaa Troudi ${ }^{(3)}$
}

(1) MMA Laboratory, Matériaux Mesures et Applications, INSAT, Institut National des Sciences Appliquées et de Technologie, Université de Carthage, Zone Urbaine Nord, 1080, Tunis, Tunisia.

(2) AMPERE Laboratory UMR CNRS 5005, Université Lyon 1, Université de Lyon, F-69622, Villeurbanne, France.

(3) RELEV, Research Unit on Renewable Energies and Electric Vehicles, Sfax Engineering School, Université de Sfax, Tunisia.

Abstract-This work presents a study of the reduction in battery stresses by using supercapacitors (SC's) in a $500 \mathrm{kVA}$ rated UPS. We aim at investigating the optimal supercapacitors-battery combination versus the SC's cost. This investigation is threefold; first, supercapacitors and battery models developed using Matlab/Simulink® are presented and validated. Second, the architecture and the simulation of the designed system that combines the SC's and the battery are shown. The supercapacitors are used as high power storage devices to smooth the peak power applied to the battery during backup-time and to deliver full power during short grid outages. By charging the SC's through the battery at a suitable rate, all impulse power demands would be satisfied by the supercapacitors.

Third, extensive simulations are carried out to determine the gain in battery RMS current, the gain in energy losses, the energy efficiency and the elimination rate of surge load power. These four performance parameters are determined by simulation and then analyzed. The influence of the SC's recharge on the performance indicators is highlighted. A thorough analysis involving optimal study proposes to draw the optimal SC's number and filter constant from the variation of the aforementioned parameters versus the cost of the SC's.

Index Terms - Supercapacitors, lead-acid battery, hybrid power sources, Uninterruptible Power Supply (UPS)

$\mathrm{SC}, \mathrm{SC}$ 's

$\mathrm{SoC}$

$P_{\text {load }}$

$P_{N}$

$P_{\text {bat }}$

$P_{s c}$

$N_{p_{-} s c}$

$N_{s \_s c}$

$W_{s c}$

$E_{s c}$

$C_{e q}$

$C_{s c}$

$U_{s c}$

$U_{b a t}$

$U_{M}$

$U_{m}$

$v_{s c}$

$V_{s c i}$

$V_{s c f}$

$P_{\text {Lm }}$

$T_{a u}$

\section{NOMENCLATURE}

Abbreviation of supercapacitor and supercapacitors, respectively

State of Charge

Load power

Nominal battery power

Battery power

Supercapacitors pack power

Number of SC's pack parallel branches

Number of SC's series elements

Energy stored in one supercapacitor

Energy stored in the supercapacitors pack

Capacitance of the SC's pack

Capacitance of one supercapacitor element

Supercapacitors pack voltage

Battery voltage

Maximum SC's pack voltage

Minimum SC's pack voltage

Voltage of a supercapacitor

Initial voltage of one supercapacitor

Final voltage of one supercapacitor

Minimum load power limit that trigs SC's recharge via the battery

Filter constant time 

$G_{-} W_{\text {losses }}$
Gain in battery losses
$G_{-} I_{R M S}$
Gain in battery RMS current
$\tau_{\text {elim }}$
Elimination rate of battery power impulses

\section{INTRODUCTION}

In many industrial sectors, high reliability power supply is required for critical loads. Uninterruptible Power Supplies (UPS) are used to improve power quality and guarantee the reliability of backup power. During voltage sags or complete interruptions of the power supply, the energy has to be supplied by local Energy Storage Systems (ESS). Conventional ESS for UPS is basically relying on the choice of good lead-acid batteries [1]. However, there are many disadvantages associated with batteries such as low power density and limited charge/discharge cycles.

Moreover, extracting pulsed power instead of average power from the battery can decrease its lifespan [2]. First, the current variations cause voltage transients that can be interpreted by the low voltage detection circuit as a discharged battery creating a premature shutdown. Second, the pulsed currents have a higher RMS value, which might cause increasing battery losses. Third, pulsating currents also reduce greatly the battery runtime [3].

A supercapacitor is a double-layer electrochemical capacitor that can store thousand times more energy than a typical capacitor. It shares the characteristics of both batteries and conventional capacitors and has an energy density about $20 \%$ of a battery. Moreover, they have almost negligible losses and long lifespan. They can process a large number of charge and discharge cycles (several hundred thousand cycles) compared to only a few thousand cycles for lead-acid batteries [4], [5] and can supply much higher currents than batteries [6].

Batteries are mostly efficient when used to supply low, reasonably steady power levels. Supercapacitors are very effective in storing charge for later use. Their leakage rate and series resistance are quite small [7], [8].

The power sharing between supercapacitors, fuel cells and batteries is a promising solution for improving the performance system due to the dynamic behavior of the SC's and their long life [9- 10].

This combination was tested successfully in many applications like Pure Battery-Powered Electric Vehicle (EV) [11], [12], [13], Hybrid Electric Vehicle (HEV) [14], [15], [16], and Fuel Cell (FC) based UPS systems [17], [18], [19], [20].

In UPS applications, batteries usually provide 5 to 15 minutes of backup min backup time power before a generator starts and is ready to accept the full load. Supercapacitors can supply only 5 to 20 seconds of backup at full power. This means that SC's could be a good battery replacement only when long runtime is not required because of their high price, their high size and mass [21], [22], [23]. Nowadays it is better to combine traditional battery for higher energy UPS and SC's for higher power UPS. It is worth mentioning that supercapacitors are experiencing high development and becoming more and more competitive in price [24].

In this paper we present a power sharing method between the supercapacitors and the lead acid battery in a $500 \mathrm{kVA}$ rated Uninterruptible Power Supply. Combining supercapacitors with battery-based UPS system gives the best of high energy and high power configurations. The supercapacitors ensure the power impulses and reduce high power demands away from the battery during the 10 min backup time. They also deliver the whole load power during outages lasting less than $10 \mathrm{~s}$. The lifetime of the batteries could then be extended.

We focus then our study of the reduction in battery stresses by the use of SC's. We aim at investigating the optimal SC's/battery combination with respect to the cost price of supercapacitors. This investigation is threefold; first, supercapacitors and battery models are developed then validated using Matlab/Simulink ${ }^{\circledR}$ software.

In a second stage, the architecture and the simulation of the designed system combining the two types of storage devices are shown. The study emphasizes on UPS autonomous running for grid faults lasting few minutes, the supercapacitors supply the transient demand of power and the battery is responsible for 
the smoothness requirement for energy. By allowing the battery to charge up the supercapacitors pack at a suitable rate, the energy stored in the SC's would be available to satisfy the maximum of the pulsating load power demands.

Finally, extensive simulations are carried out to determine the gain in battery RMS current, the gain in energy losses, the energy efficiency and the elimination rate of surge load power. These four performance parameters are determined through simulations and then analyzed. They reflect the potential decrease in battery stresses due to the SC's. We carried out a thorough analysis involving optimal study. We propose to draw the optimal SC's number and filter constant from the variation of the aforementioned parameters versus the cost price of the supercapacitors

\section{PRESENTATION OF THE STUDIED UPS}

\section{A. UPS specification}

The main specifications of the $500 \mathrm{kVA}$ UPS are:

- Power factor: $F P=0.9$,

- Total efficiency: $\eta=95 \%$,

- Nominal output voltage: $V_{a c}=400 \mathrm{~V}$,

- Nominal battery power: $P_{N}=480 \mathrm{~kW}$,

- Backup time: $T=10 \mathrm{~min}$,

- DC-bus voltage: $V_{D C}=400 \mathrm{~V}$,

- Nominal battery voltage: $U_{\text {bat_nom }}=480 \mathrm{~V}$.

Fig.1 shows a simplified electrical diagram of the UPS under consideration. Its topology is an Online/Double-Conversion system [25]. Before adding the supercapacitors (without the dotted part), in the case of interruption of the power grid from "Input1", the battery supplies immediately the full power to the inverter during short and long outages. The period of backup time is 10 minutes and it is the required time for the generator to start up and to reach its rated operation.

Referring to Standard EN 50160 [26], grid failures requirements are as follows:

- Short interruptions of voltage supply: (up to 3 minutes), few tens - few hundreds/year, duration $70 \%$ of them $<1 \mathrm{~s}$

- Long interruptions of voltage supply: (longer than 3 minutes), <10 - 50/year

We mention that in practice, these requirements are not particularly rigorous for the supplier. On the other hand, the consumer regards the limits given in EN 50160 as requirements that must be guaranteed by the supplier [26].

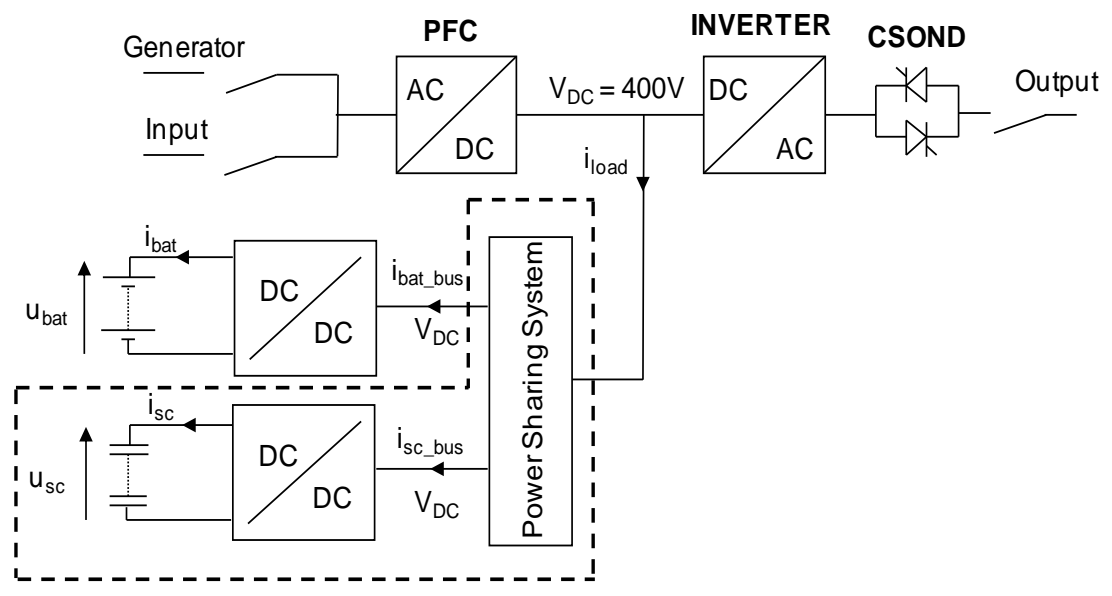

Fig. 1. Topology of the $500 \mathrm{kVA}$ UPS 


\section{B. Supercpacitors pack sizing and modeling}

We have chosen that the supercapacitors, added as high power storage devices, must supply the full power $P_{\text {load }}=P_{N}$ during $\Delta t=10 \mathrm{~s}$, the delivered energy is then estimated to be around $4.8 \mathrm{MJ}$.

The energy $E_{s c}$ stored at the voltage $U_{s c}$ of the SC's pack voltage can be expressed as follows:

$$
E_{s c}=\frac{1}{2} C_{e q} U_{s c}^{2}=\frac{1}{2} \frac{N_{p_{-} s c}}{N_{s_{-} s c}} C_{s c} U_{s c}^{2}
$$

where $C_{e q}$ is the equivalent capacity of the SC's pack, $N_{p_{-} s c}$ and $N_{s_{-} s c}$ are the number of parallel branches and the number of SC's series connections, respectively, and $C_{s c}$ is the SC capacitance.

The supercapacitors considered in this paper are the Maxwell/BCAP3000 type, rated $3000 \mathrm{~F}, 2.7 \mathrm{~V}$. having the parameters given in Table 1.

\section{TABLE I}

\section{PARAMETERS OF THE BCAP 3000 SUPERCAPACITORS}

\begin{tabular}{|c|c|c|c|}
\hline ELECTRICAL & BCAP3000 & TEMPERATURE & BCAP3000 \\
\hline Rated Capacitance ${ }^{1}$ & $3,000 \mathrm{~F}$ & \multirow{2}{*}{$\begin{array}{l}\text { Operating temperature range } \\
\text { (Cell case temperature) }\end{array}$} & \multirow{5}{*}{$\begin{array}{l}-40^{\circ} \mathrm{C} \\
65^{\circ} \mathrm{C}\end{array}$} \\
\hline Minimum Capacitance, initial' & $3,000 \mathrm{~F}$ & & \\
\hline Maximum ESR ${ }_{D C}$, initial' & $0.29 \mathrm{~m} \Omega$ & Minimum & \\
\hline Rated Voltage & $2.70 \mathrm{~V}$ & Maximum & \\
\hline Absolute Maximum Voltage ${ }^{11}$ & $2.85 \mathrm{~V}$ & $\begin{array}{l}\text { Storage temperature range } \\
\text { (Stored uncharged) }\end{array}$ & \\
\hline $\begin{array}{l}\text { Maximum Continuous Current } \\
\left(\Delta \mathrm{T}=15^{\circ} \mathrm{C}\right)^{2}\end{array}$ & $130 \mathrm{~A}_{\mathrm{RMS}}$ & Minimum & $-40^{\circ} \mathrm{C}$ \\
\hline $\begin{array}{l}\text { Maximum Continuous Current } \\
\left(\Delta \mathrm{T}=40^{\circ} \mathrm{C}\right)^{2}\end{array}$ & $210 A_{\text {RMS }}$ & $\begin{array}{l}\text { Maximum } \\
\text { PHYSICAL }\end{array}$ & BCAP3000 \\
\hline Maximum Peak Current, 1 second $^{3}$ & $2,200 \mathrm{~A}$ & Mass, typical & $510 \mathrm{~g}$ \\
\hline Leakage Current, maximum ${ }^{4}$ & $5.2 \mathrm{~mA}$ & Terminals & $\begin{array}{l}\text { Threaded or } \\
\text { Weldable }\end{array}$ \\
\hline & & Vibration & IEC 16750 \\
\hline & & Shock & SAE J2464 \\
\hline
\end{tabular}

1

It is usually allowed to utilize $75 \%$ of the energy stored in the SC's pack by discharging the pack from its rated voltage $U_{M}=300 \mathrm{~V}$ (about $80 \%$ of the DC-bus voltage [27]) to the half of that value equal to $U_{m}=150 \mathrm{~V}$. Every elementary SC in then discharged from an initial voltage $V_{s c i}=2.7 \mathrm{~V}$ to a final voltage $V_{s c f}=1.35 \mathrm{~V}$. Further, the internal losses in the SC's may be taken into account through the efficiency coefficient $k=0.9$ [27]. The energy extracted from the SC's can then be written as:

$P_{N} \Delta t=k \times\left(\frac{1}{2} C_{e q} U_{M}{ }^{2}-\frac{1}{2} C_{e q} U_{m}{ }^{2}\right)$

This leads, by considering an energy of $4.8 \mathrm{MJ}$, to a SC's pack having an equivalent capacitance $C_{e q}=158 \mathrm{~F}$. Referring to the initial voltage of the SC's pack, we obtain $N_{s_{-} s c}=112$ and $N_{p_{-} s c}=6$.

To optimize the supercapacitors combination with the battery in UPS applications, we need to establish a model to describe the supercapacitor behavior during fast charge and discharge cycles. We consider the equivalent electric circuit with two RC branches proposed by [28], [29] as shown in figure 2. 


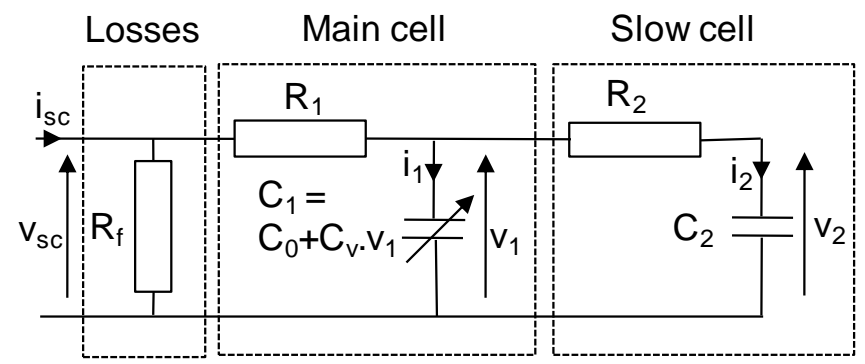

Fig. 2. Supercapacitor simplified circuit: two branches model

The main capacitance $C_{1}$ (differential capacitance [28]) depends on the voltage $v_{1}$. It consists of a constant capacity $C_{0}$ (in F) and a constant parameter $C_{v}$ (in F/V) and it is written as $C_{1}=C_{0}+C_{v} v_{1}$. The $R_{1} C_{1}$ branch determines the immediate behavior of the supercapacitor during rapid charge and discharge cycles in a few seconds.

The $R_{2} C_{2}$ cell is the slow branch. It completes the first cell in longtime range in order of a few minutes and describes the internal energy distribution at the end of the charge (or discharge). The equivalent parallel resistance $R_{f}$ represents the leakage current and can be neglected during fast charge/discharge of the supercapacitor.

To identify the parameters of the proposed model, we carried out a single fast controlled charge/discharge test at constant current $250 \mathrm{~A}$ and -250 A, respectively. The experimental method which determines the parameters of the supercapacitor equivalent circuit is described in [28].

The obtained values are:

- $R_{1}=0.360 \mathrm{~m} \Omega$,

- $C_{0}=2100 \mathrm{~F}$,

- $C_{v}=623 \mathrm{~F} / \mathrm{V}$,

- $R_{2}=1.92 \Omega$,

- $C_{2}=172 \mathrm{~F}$,

The simulation circuit with Matlab $\backslash$ Simulink ${ }^{\circledR}$ of the supercapacitors pack is illustrated in figure 3.

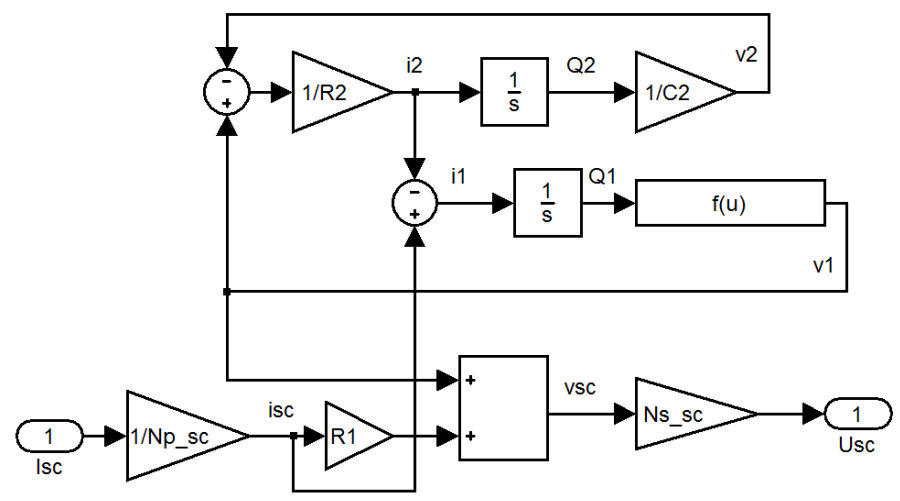

Fig. 3. Matlab simulation model of Supercapacitors pack

This circuit is based on the following equations (leakage current of supercapacitor is neglected):

$$
U_{s c}=N_{s_{-} s c} v_{s c}=N_{s_{-} s c}\left(v_{1}+R_{1} i_{s c}\right)=N_{s_{-} s c}\left(v_{1}+R_{1} \frac{I_{s c}}{N_{p_{-} s c}}\right)
$$

with:

- $U_{s c}$ and $I_{s c}$ are the SC's pack voltage and current respectively, 
- $v_{s c}$ and $i_{s c}$ are the elementary supercapacitor voltage and current respectively.

The voltage $v_{2}$ in the secondary capacity $C_{2}$ is given by:

$v_{2}=\frac{1}{C_{2}} \int i_{2} d t=\frac{1}{C_{2}} \int \frac{1}{R_{2}}\left(v_{1}-v_{2}\right) d t$

Let $Q_{2}$ the instantaneous charge of $C_{2}$, we have:

$Q_{2}=\int i_{2} d t$

The current $i_{1}$ going in the main capacitor $C_{1}$ is expressed as:

$i_{1}=i_{s c}-i_{2}$

On the other hand, $i_{1}$ is expressed in terms of the instantaneous charge $Q_{1}$ and $C_{1}$ as:

$i_{1}=C_{1} \frac{d v_{1}}{d t}=\frac{d Q_{1}}{d t}=\left(C_{0}+C_{v} \cdot v_{1}\right) \frac{d v_{1}}{d t}$

where the charge $Q_{1}$ is:

$Q_{1}=C_{0} v_{1}+\frac{1}{2} C_{v} \cdot v_{1}^{2}$

The one supercapacitor element is supposed initially to be fully charged at $V_{s c i}=v_{1 i}=v_{2 i}=2.7 \mathrm{~V}$. The initial values are then:

$Q_{2 i}=C_{2} v_{2 i}$

$Q_{1 i}=C_{0} v_{1 i}+\frac{1}{2} C_{v} \cdot v_{1 i}^{2}$

The equation (10) leads to the inverse relationship between $v_{1}$ and $Q_{1}$ that represents the function $\mathrm{f}(\mathrm{u})$ in Fig. 3 and it is given by:

$v_{1}=\frac{-C_{0}+\sqrt{C_{0}^{2}+2 C_{v} Q_{1}}}{C_{v}}$

In Fig. 4 we represent the experimental results compared to the simulation carried out using Matlab/Simulink ${ }^{\circledR}$ for the charge/discharge test at constant current $250 \mathrm{~A}$ and $-250 \mathrm{~A}$. We observe that the $\mathrm{SC}$ 's model is in very good agreement with the experimental results. 

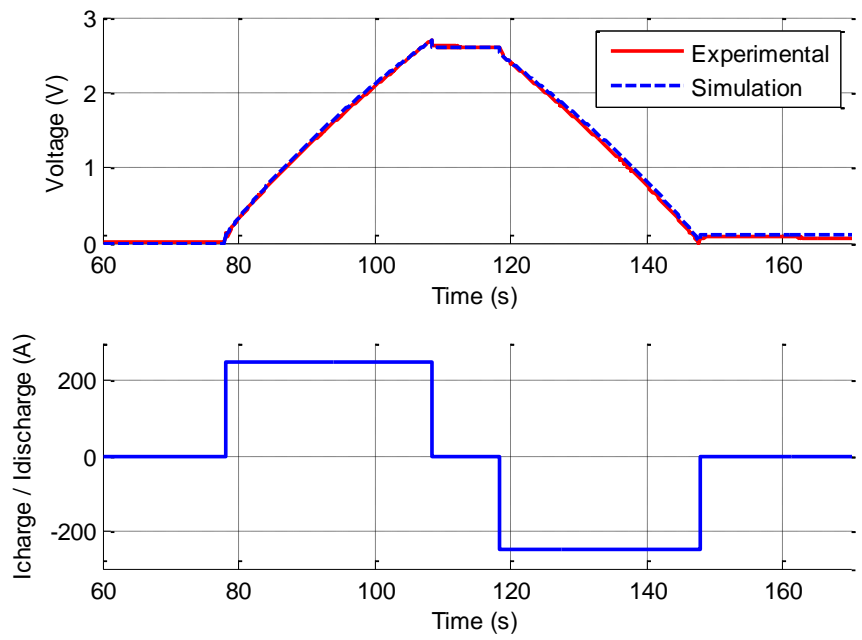

Fig. 4. Comparison between simulation and experimental results for a supercapacitor charge and discharge cycle

Finally, we verify that the sized supercapacitors pack fulfills the UPS specifications set before. In fact, the instantaneous energy $W_{s c}$ stored in the main branch of an elementary supercapacitor is given by:

$W_{s c}=\int v_{1} d Q_{1}$

By neglecting the energy dissipated in $R_{1}$ and referring to Eq. (7), we obtain the energy $W_{s c}$ stored in one SC element: as follows:

$W_{s c}=\left(\frac{1}{2} C_{0} v_{s c}^{2}+\frac{1}{3} C_{v} v_{s c}^{3}\right)$

The total energy stored in the SC's pack is then given by:

$E_{s c}=N_{s_{-} s c} \times N_{p_{-} s c} \times\left(\frac{1}{2} C_{0} v_{s c}^{2}+\frac{1}{3} C_{v} v_{s c}{ }^{3}\right)$

The SC's voltage element drops from an initial value $V_{s c i}=2.7 \mathrm{~V}$ to a final value $V_{s c f}=1.35 \mathrm{~V}$, the difference between initial energy $E_{s c i}$ and final energy $E_{s c f}$ of the SC's pack multiplied by the efficiency coefficient $\mathrm{k}$ is equal to 5.6 MJ. This means that the SC's pack sizing is in good concordance with the energy $P_{N} \Delta t=4.8 \mathrm{MJ}$ specified previously.

\section{Battery sizing and modeling}

For the studied $500 \mathrm{kVA}$ UPS, the battery chosen by the UPS manufacturer is made of 2226 elementary lead-acid batteries (type VISION rated 7Ah 12V CP1270), the number of series and parallel connections are $N_{s_{-} \text {bat }}=42$ and $N_{p_{-} b a t}=53$, respectively.

We notice that for a full power $P_{N}=480 \mathrm{~kW}$ extracted from the battery during the ten-minute autonomous operation, each elementary battery is discharged at $P_{b a t}=216 \mathrm{~W}$. Since each battery is made of 6 cells, each cell is then discharged at $P_{\text {cell }}=36 \mathrm{~W}$.

Referring to the one cell discharge table of the $7 \mathrm{Ah} 12 \mathrm{~V}$ battery (cf. table II, line 1, column 2 ), the end point voltage of every cell is about $1.6 \mathrm{~V}$, which means that the total battery end voltage is almost equal to $400 \mathrm{~V}$. In conclusion, the battery voltage drops during a constant power discharge at $P_{N}=480 \mathrm{~kW}$ from $555 \mathrm{~V}(2.2 \mathrm{~V}$ per cell $)$ to $400 \mathrm{~V}$. As the DC-bus voltage is equal to $400 \mathrm{~V}$, the battery is connected to the DC-bus via a buck DC/DC converter (cf. Fig. 1). 
In order to simulate the UPS nominal running, we need a model of the battery that represents accurately its behavior during charge and discharge cycles for few minutes.

Battery modeling is much more complicated than that of SC's for many reasons to name a few, internal temperature and State of Charge (SoC) of battery model's parameters are known to be hardly measured. Many analytical models have been studied and experimentally validated [30], [31], [32].

\section{TABLE II}

\section{DISCHARGE TABLE OF ONE CELL OF THE 7AH 12V CP1270 VISION BATTERY}

Discharge Constant Power (Watts at $77^{\circ} \mathrm{F} 25^{\circ} \mathrm{C}$ )

\begin{tabular}{|c|c|c|c|c|c|c|c|c|c|}
\hline $\begin{array}{c}\text { End Point } \\
\text { Volts/Cell }\end{array}$ & $5 \mathrm{~min}$ & $10 \mathrm{~min}$ & $15 \mathrm{~min}$ & $30 \mathrm{~min}$ & $45 \mathrm{~min}$ & $1 \mathrm{~h}$ & $2 \mathrm{~h}$ & $3 \mathrm{~h}$ & $5 \mathrm{~h}$ \\
\hline $1.60 \mathrm{~V}$ & 52.0 & 35.1 & 27.5 & 15.2 & 11.50 & 8.97 & 5.06 & 3.59 & 2.33 \\
\hline $1.65 \mathrm{~V}$ & 49.4 & 33.3 & 26.5 & 14.6 & 11.00 & 8.59 & 4.94 & 3.50 & 2.29 \\
\hline $1.70 \mathrm{~V}$ & 46.9 & 31.6 & 25.4 & 14.0 & 10.50 & 8.23 & 4.80 & 3.40 & 2.25 \\
\hline $1.75 \mathrm{~V}$ & 44.5 & 29.8 & 24.3 & 13.4 & 10.10 & 7.99 & 4.65 & 3.30 & 2.21 \\
\hline $1.80 \mathrm{~V}$ & 41.6 & 28.0 & 23.3 & 12.9 & 9.75 & 7.62 & 4.50 & 3.19 & 2.15 \\
\hline
\end{tabular}

The battery model used in this paper is based on the circuit proposed by [33]. All the model parameters are determined based on the discharge curve as shown in Fig. 5.

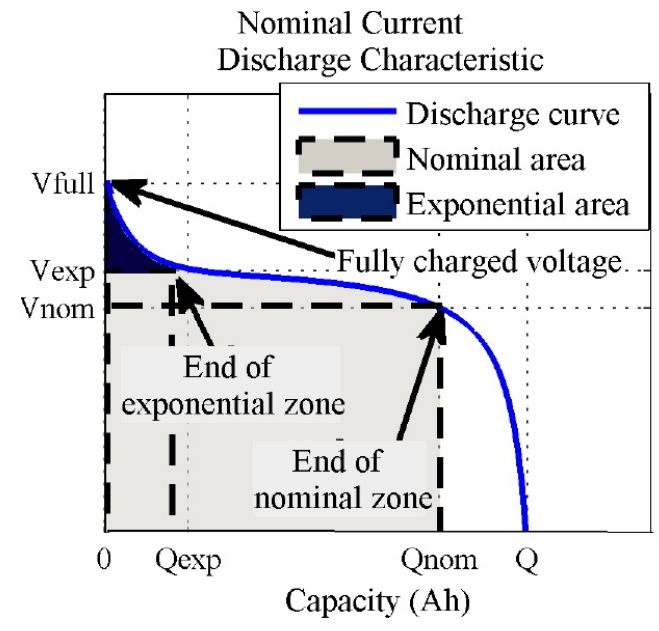

Fig. 5. Typical discharge curve [33]

The main feature of this model is the accuracy of the battery's behavior with respect to current variation and the battery's SoC. Furthermore, the open circuit voltage (OCV) is taken as a function of the SoC.

A term concerning the polarization voltage is added to better represent the OCV behavior and the term concerning the polarization resistance is slightly modified [33], [34].

The battery voltage $v_{b a t}$ is expressed as follows:

$v_{b a t}=E_{0}-K \frac{Q}{Q-i t} .($ it $)-R_{b a t} i+A \cdot \exp (-B . i t)-K \frac{Q}{Q-i t} \cdot i^{*}$

where:

- $E_{0}=$ battery constant voltage $(\mathrm{V})$,

- $K=$ polarization constant $(\mathrm{V} / \mathrm{Ah})$ or polarization resistance $(\Omega)$,

- $Q=$ battery capacity (Ah), 
- $i t=\int i d t=$ actual battery charge $(\mathrm{Ah})$,

- $A=$ exponential zone amplitude (V),

- $B=$ exponential zone time constant inverse $\left(\mathrm{Ah}^{-1}\right)$,

- $R_{\text {bat }}=$ internal resistance $(\Omega)$,

- $i=$ battery current (A),

- $i^{*}=$ filtered current at low frequency (A).

The main feature of this model is that only three points of the discharge curve are required to obtain all the parameters. The points are the fully charged voltage $\left(V_{\text {full }}\right)$, the end of the exponential zone $\left(V_{\text {exp }}, Q_{\text {exp }}\right)$ and the end of the nominal zone $\left(V_{\text {nom }}, Q_{\text {nom }}\right)$, respectively.

We suppose that the battery is discharged at the nominal power $P_{\mathrm{N}}=480 \mathrm{~kW}$, its voltage drops from $555 \mathrm{~V}$ to $400 \mathrm{~V}$. The total battery current rises from 865 A to approximately $1200 \mathrm{~A}$. So the current extracted from every element varies between $16 \mathrm{~A}$ and $23 \mathrm{~A}$. For an operating power range between $0.2 P_{N}$ and $0.9 P_{N}$, the current varies from $4.5 \mathrm{~A}$ to $20 \mathrm{~A}$. The discharge curves used to perform the battery model are chosen in this discharge current range. Fig. 6 shows the simulation results superimposed on the discharge curves for currents $I_{d}=4.56 \mathrm{~A}, I_{d}=7 \mathrm{~A}$ and $I_{d}=21 \mathrm{~A}$. We notice that the battery model elaborated with Matlab/Simulink ${ }^{\circledR}$ draws with good accuracy the battery behavior at steady state discharge and at variable discharge currents.

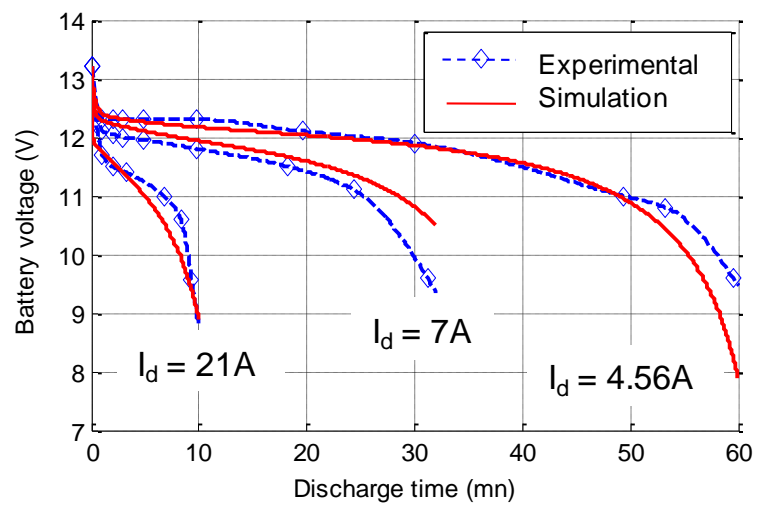

Fig. 6. Experimental and simulated battery discharge curves

\section{DESIGN OF BATTERY-SUPERCAPACITORS COMBINATION}

\section{A. Combination without control system}

Firstly, the battery and the supercapacitors have been combined in parallel without control system as shown in Fig. 7. The DC/DC and the AC/DC converters are supposed to be ideal without losses. The DC bus voltage $V_{\mathrm{DC}}$ is equal to $400 \mathrm{~V}$.

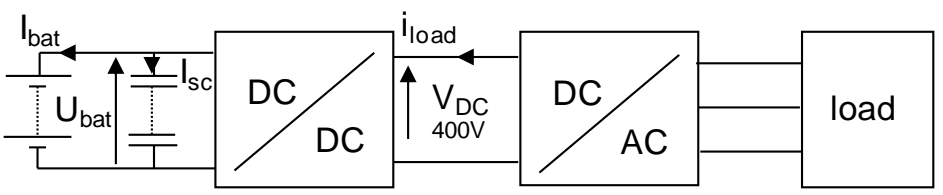

Fig. 7. Parallel combination between SC's and battery

The supercapacitors are configured as such to have approximately the same total number calculated in the previous section (672 cells) and to ensure initial voltage almost equal to $560 \mathrm{~V}$ (OCV battery voltage). We have then $N_{s_{-} s c}=205$ and $N_{p_{-} s c}=4$.

Fig. 8 represents the evolution of the $U_{b a t}$ voltage versus time during the 10 minutes backup time. Note that $U_{b a t}$ drops from an initial value of $560 \mathrm{~V}$ to a final value of $480 \mathrm{~V}$. 


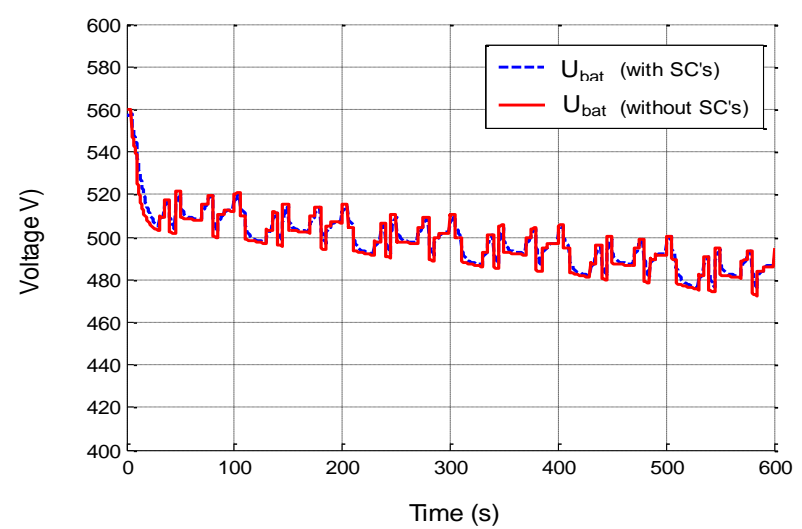

Fig. 8. Battery voltage versus time

However, the battery and the SC's power waveforms represented in Fig. 9 (a) show that the power delivered by the battery has transient peaks during all the backup time. These instantaneous power demands applied to the battery affect dramatically its lifetime. We also remark in Fig. 9 (b) that the SC's power have charge/discharge phases that are not controlled and may cause the failure of the supercapacitors.

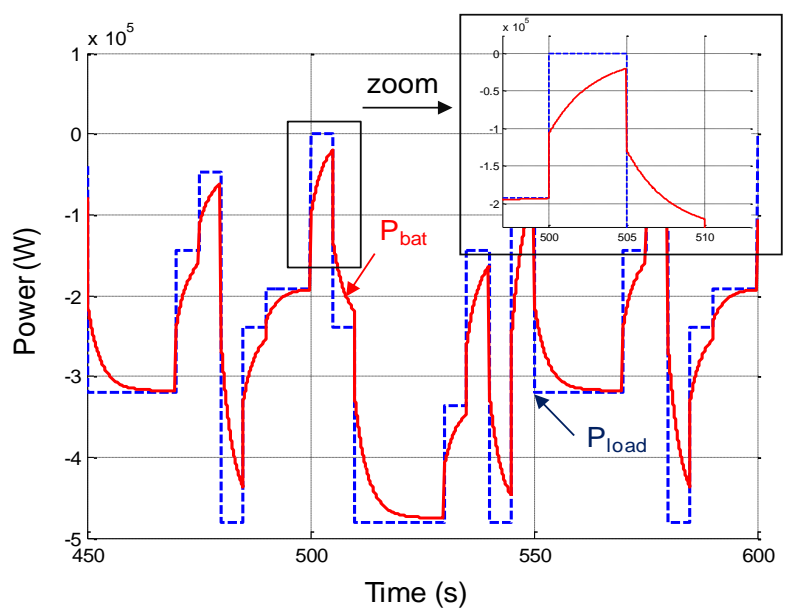

(a) $P_{\text {load }}$ and $P_{\text {bat }}$

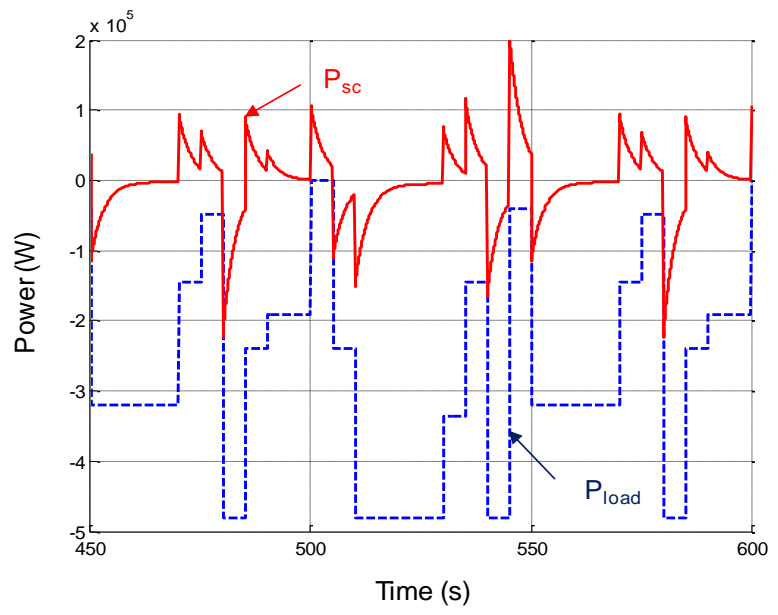

(b) $P_{\text {load }}$ and $P_{s c}$

Fig. 9. $P_{\text {load }}, P_{b a t}$ and $P_{s c}$ without control system 


\section{B. Controlled SC's-battery Combination}

The control system presented in this section is designed to benefit the fast charge and discharge capability of the supercapacitors in order to reduce the battery stresses due to instantaneous power demands. The purpose of the combination between SC's and the battery is to make the SC's supply the power transients and to smooth the high power demands applied to the battery during autonomous operation [35]. Fig. 10 shows the new UPS topology counting the control system for power sharing between SC's and the battery.

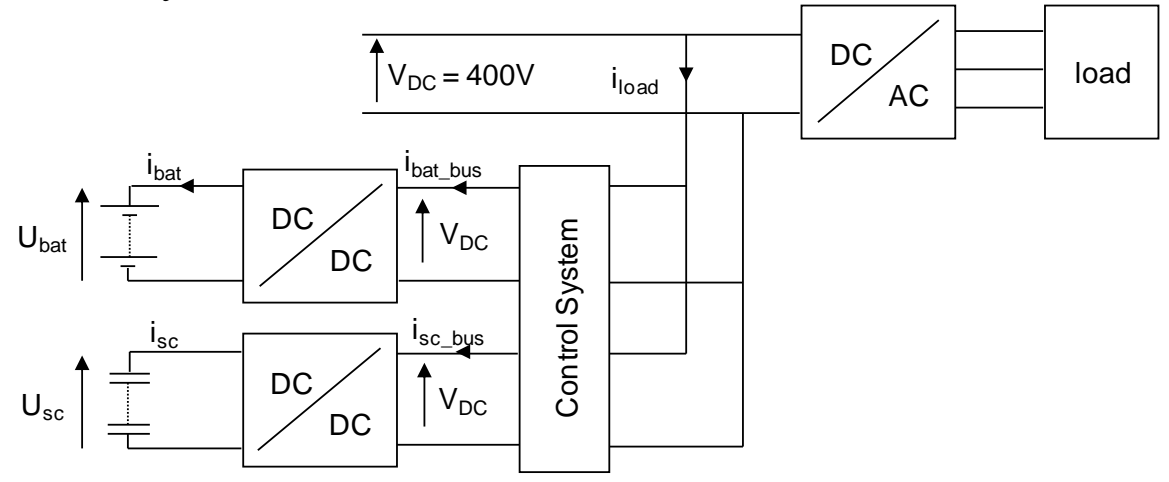

Fig. 10. Topology of the controlled SC's/battery combination

The DC/DC converters are supposed to be without losses and modeled as DC ideal bi-directional transformers. The input currents of the converters associated with the battery and the SC's pack, respectively $i_{\text {bat_bus }}$ and $i_{\text {s__bus }}$ (cf. Fig. 10) are controlled by the power sharing system. This control system performs according to the state of charge of the SC's pack and to the shape of the load power. The load current $i_{\text {load }}$ and the load power $P_{\text {load }}$ are distributed to the battery and the SC's according to the principle represented in Fig. 11.

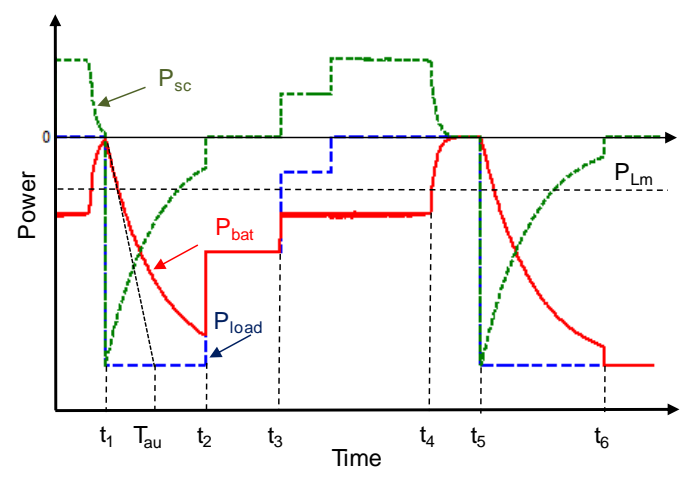

Fig. 11: Principle of power sharing between SC's and the battery

where:

- $P_{\text {load }}$ is the load power,

- $P_{b a t}$ is the battery power,

- $P_{s c}$ is the SC's pack power,

- $P_{L m}$ is the limit load power.

- $P_{I V}$ is the initial value of the battery power.

1- At time $t_{1}$, the battery is subjected to a rising power requested by the load. A low-pass filter is applied to the load current diverting sudden power variation to the supercapacitors. The equations of this first phase can be written as follows: 


$$
P_{b a t}=P_{l o a d}\left[1-\exp \left(-\frac{t}{T_{a u}}\right)\right]+P_{I V}
$$

The SC's power is then given by:

$$
P_{s c}=P_{l o a d}-P_{b a t}
$$

2- The constant $T_{a u}$ characterizes the dynamic of the low-pass filter. It is adjustable and can act on the discharge time of the SC's especially on the smoothing degree of the peak power applied to the battery.

3- At time $t_{2}, P_{\text {load }}<P_{b a t}$, the battery supplies a full load power and the low-pass filter operation is canceled.

4- At time $t_{3}$, the load power $P_{\text {load }}$ is less than a load power limit $P_{L m}$, the battery supplies both the load and the SC's pack with energy intended to recharge the supercapacitors.

5- At time $t_{4}$, the SC's voltage reaches its maximal tolerated value, the deterioration of supercapacitors is avoided by stopping the recharge process.

6- At time $t_{5}$, a new power demand occurs and the low-pass filter is applied again, the SC's pack is now fully charged and has sufficient energy to meet again the power impulses.

7- At time $t_{6}$, the SC's are discharged at a rate of $75 \%$ and their voltage has reached its minimum value of $150 \mathrm{~V}$. The SC's pack is stopped and the full power is transferred to the battery.

The flowchart in Fig. 12 summarizes the principle of power distribution between the battery and the supercapacitors.

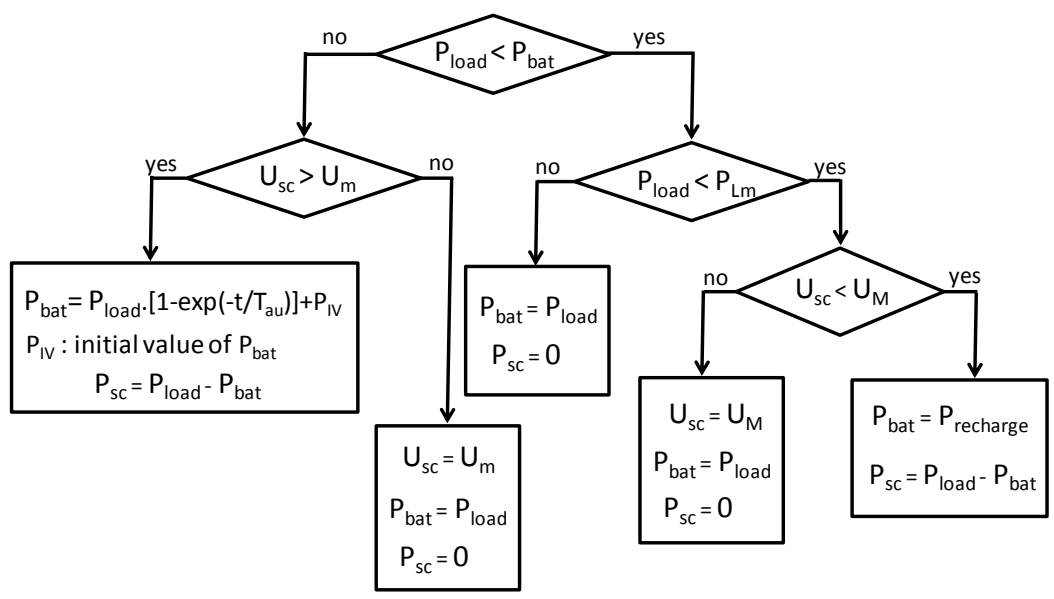

Fig. 12. Chart of the SC's/battery combination system

\section{RESULTS OF THE SC'S/BATTERY COMBINATION}

We examined at the first step the combination of the supercapacitors with the battery during the UPS backup time of 10 minutes. A load power profile, rich in harmonics, represented in Fig. 13 is considered. This profile has been provided by APC by Schneider Electric and that is typical for and IT load. It consists of a repetitive 100 seconds cycle during all the backup time $T=600 \mathrm{~s}$. 


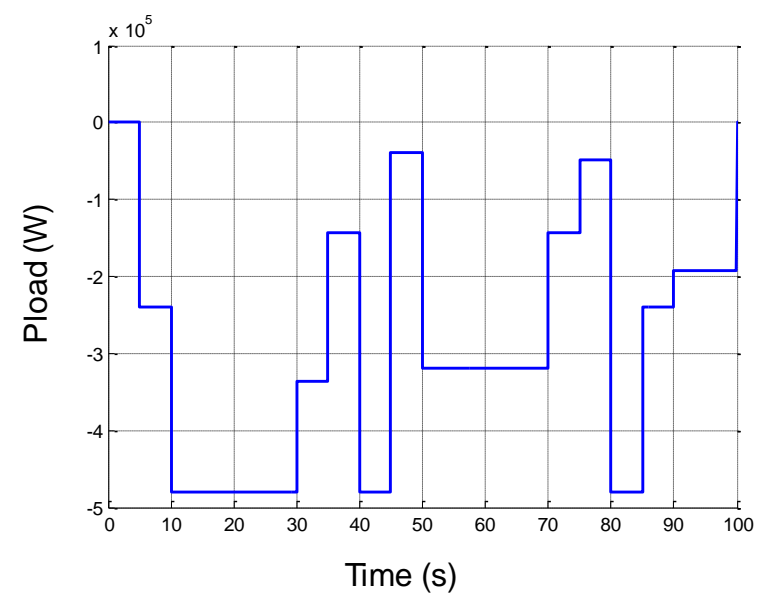

Fig. 13. Typical harmonic load power of an UPS

\section{A. Combination without SC's recharging}

The SC's supply the transient power demands without being recharged through the battery. Firstly, we show in Fig. 14 the load power $P_{\text {load }}$, the battery power $P_{b a t}$ and SC's power $P_{s c}$ obtained by simulation for a filter constant $T_{a u}=2 \mathrm{~s}$.

The total number of supercapacitors is $672\left(N_{s_{-} s c}=112\right.$ and $\left.N_{p_{-} s c}=6\right)$. For a price of around $0.015 € / \mathrm{F}$ considered (price usually found today for large quantities), the total cost of the SC's pack is about $30 \mathrm{k} €$. The SC's recharging through the battery is inhibited.

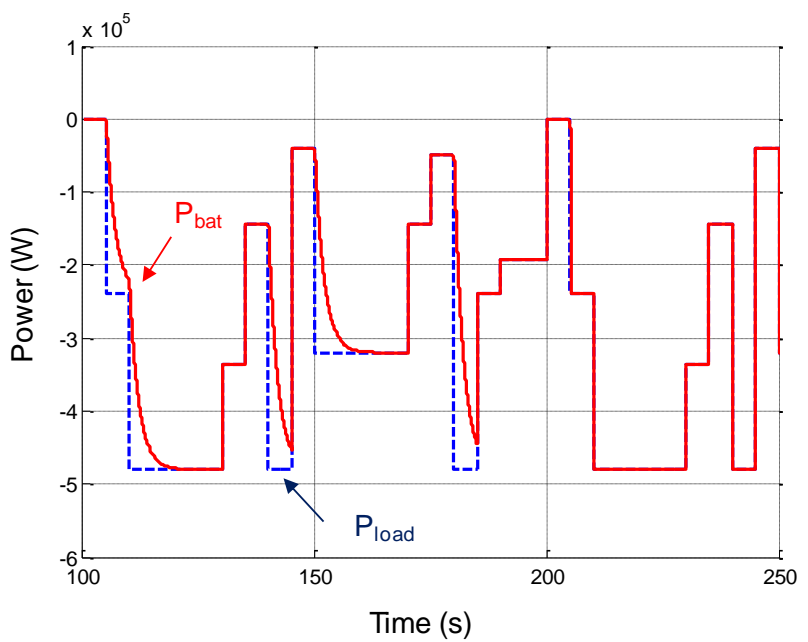

(a) $P_{\text {load }}$ and $P_{b a t}$

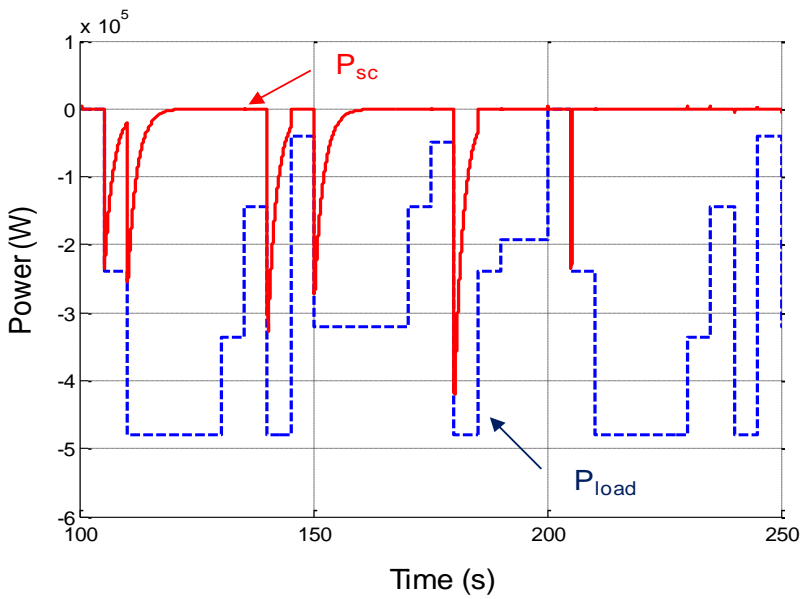


(b) $P_{\text {load }}$ and $P_{s c}$

Fig. 14. Power waveforms with control system: $P_{\text {load }}, P_{b a t}$ and $P_{s c}$

We notice form Fig. 14 that the SC's ensure the sudden power demands but only for a period of about $200 \mathrm{~s}$. Beyond that time, the battery supplies the full power until the end of the backup time of 10 minutes.

In fact, Fig. 15 showing the evolution of the battery voltage $U_{b a t}$ and the SC's voltage $U_{s c}$, confirms that the SC's are stopped at about $200 \mathrm{~s}$ since $U_{s c}$ has reached its minimum value of approximately $150 \mathrm{~V}$.

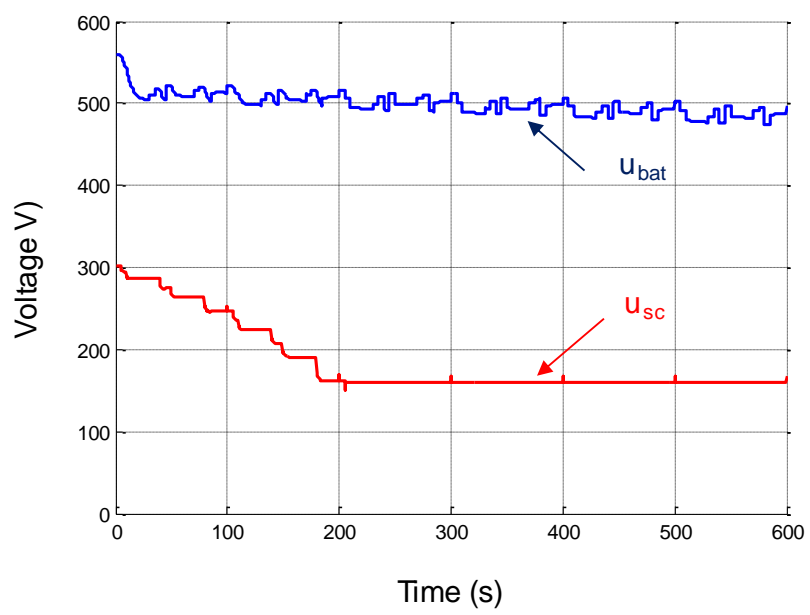

Fig. 15. Waveforms of $U_{b a t}$ and $U_{s c}$ for $N_{p_{-} s c}=6 N_{s_{-} s c}=112$ and $T_{a u}=2 \mathrm{~s}$

Secondly, we observed the influence of the filter constant $T_{a u}$ on the system performance, and the possibility to enhance the power extracted from the battery by varying the SC's pack number. A special attention is given to the cost of the SC's pack.

The system simulation was performed for different values of filter constant $\left(T_{a u}=1 \mathrm{~s}, 2 \mathrm{~s}, 5 \mathrm{~s}\right.$ and $\left.10 \mathrm{~s}\right)$ and for a number of parallel SC's branches varying from 6 to 60 . The total cost of the SC's pack varies then from $30 \mathrm{k} €$ (kEuros) to $300 \mathrm{k} €$ (about $0.015 € /$ Farad).

The battery/SC's hybrid systems have experimentally demonstrated longer operating times compared to systems without supercapacitors [36], [37], [38]. In order to examine the effect of the designed SC'sbattery combination on the system performance versus $T_{a u}$ and $N_{p_{-} s c}$, we based our study on four performance indicators that are [3], [39]:

- Gain in battery RMS current,

- Gain in battery energy losses,

- Total energy efficiency,

- Elimination rate of the power peaks.

The optimal combination is then investigated taking into account the total cost of the SC's.

1. Gain in battery RMS current

The RMS battery current gives an approximate image of the relative ohmic losses of the battery internal resistance where we neglect the chemical processes. This parameter is only used as a first step in the evaluation, where the actual battery current $\left(I_{R M S}\right)$ is compared to the battery current for the system without SC's pack $\left(I_{R M S_{-} r e f}\right)$. The gain ratio is given in percent as follows:

Gain_I $I_{R M S}(\%)=\frac{I_{R M S_{-} r e f}-I_{R M S}}{I_{R M S_{-} r e f}} \times 100$ 
Fig. 16 (a) illustrates the RMS current-gain for a variable filter constant $T_{a u}=1 \mathrm{~s}, 2 \mathrm{~s}, 5 \mathrm{~s}$ and $10 \mathrm{~s}$ and for variable number of parallel SC's branches $N_{p_{-} s c}$ from 6 to 60 branches. Fig. 16 (b) shows the RMS current-gain divided by the cost of the SC's pack.

We notice from Fig. 16 (a) that the RMS current-gain increases according to the number of parallel SC's branches and to the filter constant. We also remark that the gain reaches an upper limit versus increasing parallel connections after which there is no enhancement for the RMS current-gain. On the other side, Fig. 16 (b) shows a maximum value of gain/cost of about 120 for increasing $T_{a u}$ and $N_{p_{-} s c}$.

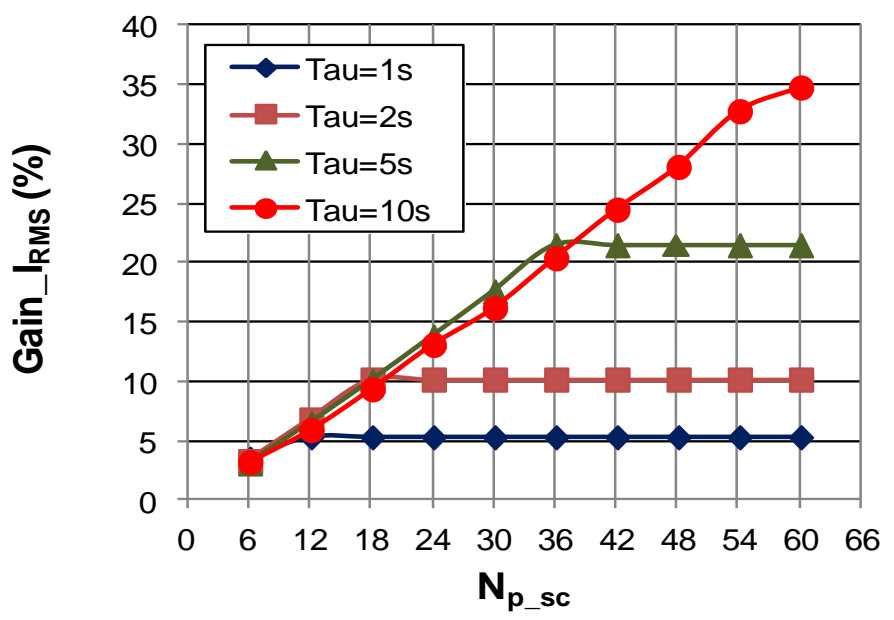

(a)

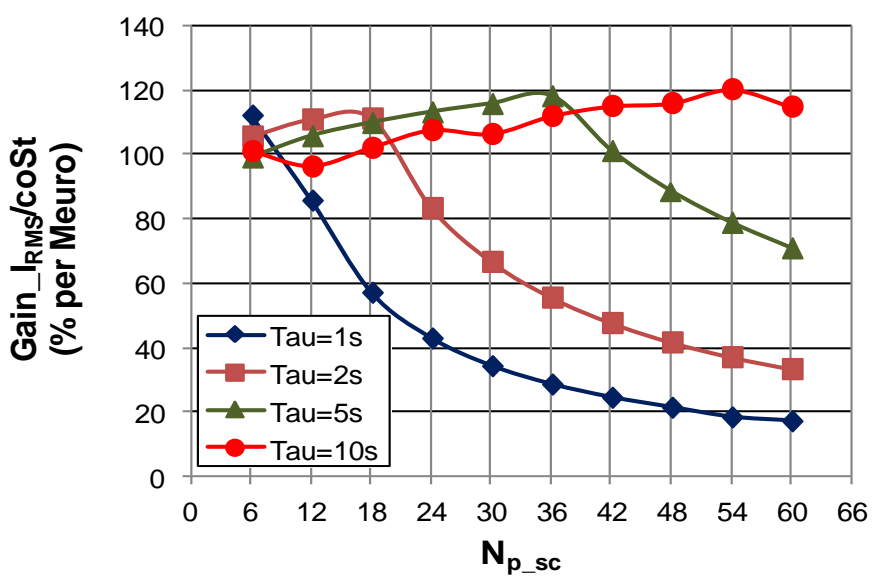

(b)

Fig. 16. Gain in RMS current versus $T_{a u}$ and $N_{p_{-} s c}$

\section{Gain in battery energy losses}

The reduction of the battery stresses are an important issue of this work. The total loss of energy in the battery is obtained from the Tremblay model [33]. The actual battery losses $\left(W_{\text {losses }}\right)$ are compared to the battery losses for the system without SC's pack ( $\left.W_{\text {losses_ref }}\right)$. The gain ratio is given in percent and it is calculated as:

Gain_W $W_{\text {losses }}(\%)=\frac{W_{\text {losses_ref }}-W_{\text {losses }}}{W_{\text {lossess_rf }}} \times 100$

Fig. 17 (a) and Fig. 17 (b) illustrate the evolution of the gain in battery energy losses and the gain per 
cost, according to $T_{a u}$ and $N_{p_{-} s c}$, respectively.

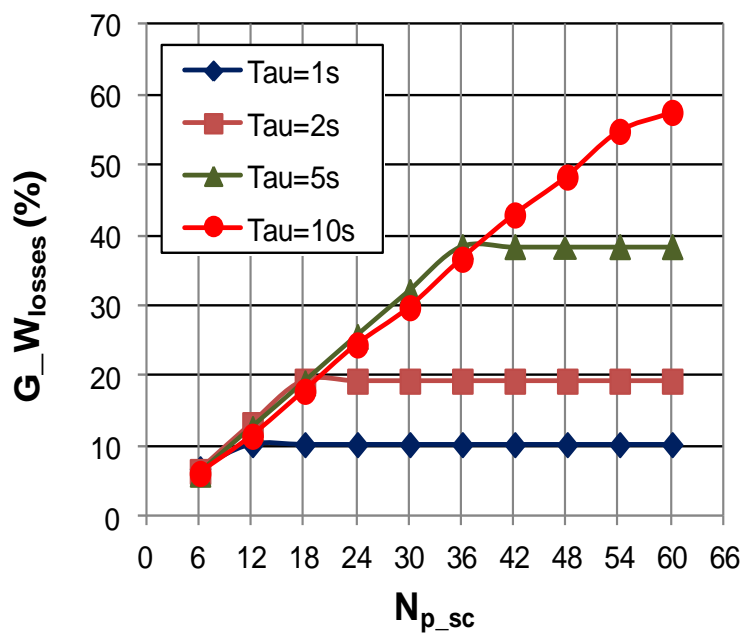

(a)

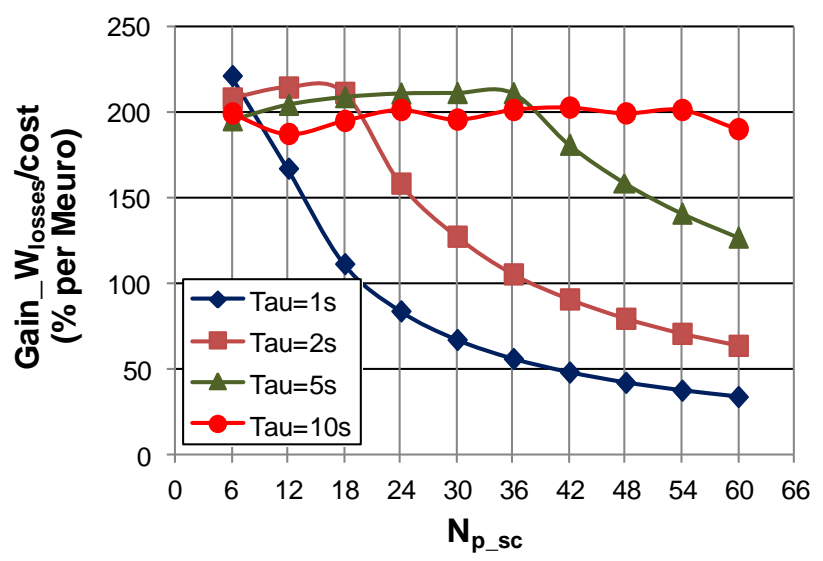

(b)

Fig. 17. Gain in battery losses versus $T_{a u}$ and $N_{p_{-} s c}$

As for RMS current-gain, the gain in battery energy losses is enhanced with increasing constant filter and SC's parallel branches until an upper limit beyond which no improvement occurs. Contrariwise, the gain divided by the cost reaches a maximum of 220 for increasing $T_{a u}$ and $N_{p_{-} s c}$ well-marked for $T_{a u}=1 \mathrm{~s}$ and $N_{p_{-} s c}=6$ branches.

3. Total energy efficiency

All the UPS components undergo losses, for example energy losses in battery, balancing circuitry of the SC's pack, DC/DC converter, cables and switching losses. Even though the reducing of the battery losses is emphasized in this work, the overall efficiency is also an important parameter since all losses in the system generate heat and, consequently, demand proper cooling.

The total energy efficiency is calculated as the ratio between the energy absorbed by the load and the energy extracted from the battery added to the energy absorbed/supplied from the SC's. Only the losses in the battery and the SC's are considered. They are included in the calculations. The energy efficiency is written as follows: 
$\eta_{g l o b a}(\%)=\frac{E_{\text {load }}}{E_{b a t}+E_{s c}} \times 100=\frac{\int_{0}^{T} P_{\text {load }} d t}{\int_{0}^{T}\left[\left(u_{b a t}-R_{b a t} \cdot i_{b a t}\right) \cdot i_{b a t}+\left(E_{s c f}-E_{s c i}\right)\right] d t}$

where:

- $E_{\text {load }}$ : total energy supplied/absorbed by the load during backup time $T=10 \mathrm{~min}$,

- $E_{b a t}$ : energy extracted from the battery added to the losses in battery resistance $R_{b a t}$,

- $E_{s c}$ : energy spplied/absorbed from the SC's added to the losses in the pack internal resistance,

- $E_{s c f}, E_{s c i}$ initial and final stored energies in the main capacitive elements of the SC's (cf. Fig. 2).

Fig. 18 shows the evolution of the energy efficiency versus $T_{a u}$ and $N_{p_{-} s c}$.

We note a very good overall efficiency of the system. The calculation of the efficiency would be more accurate if the losses in the DC/DC converters were taken into account. Fig 18 (b) shows a maximum efficiency per cost for $N_{p_{-} s c}=6$.

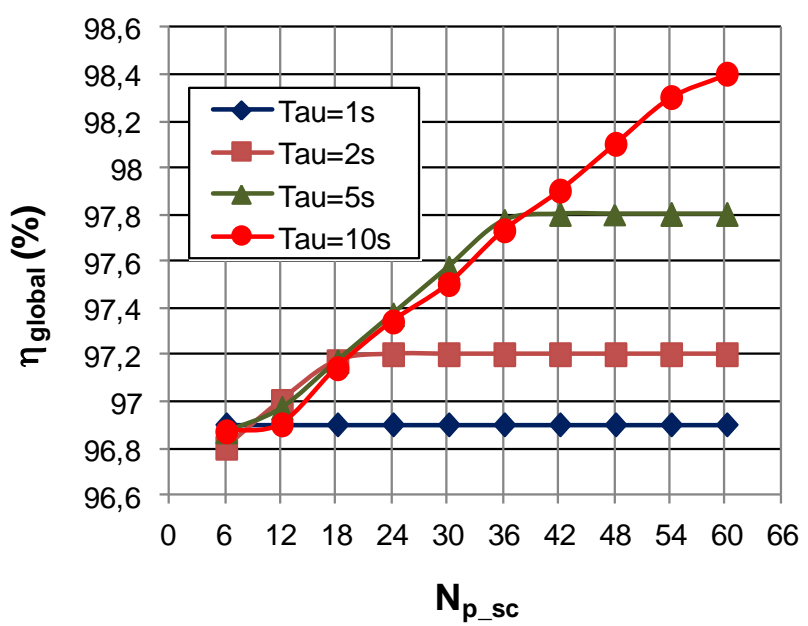

(a)

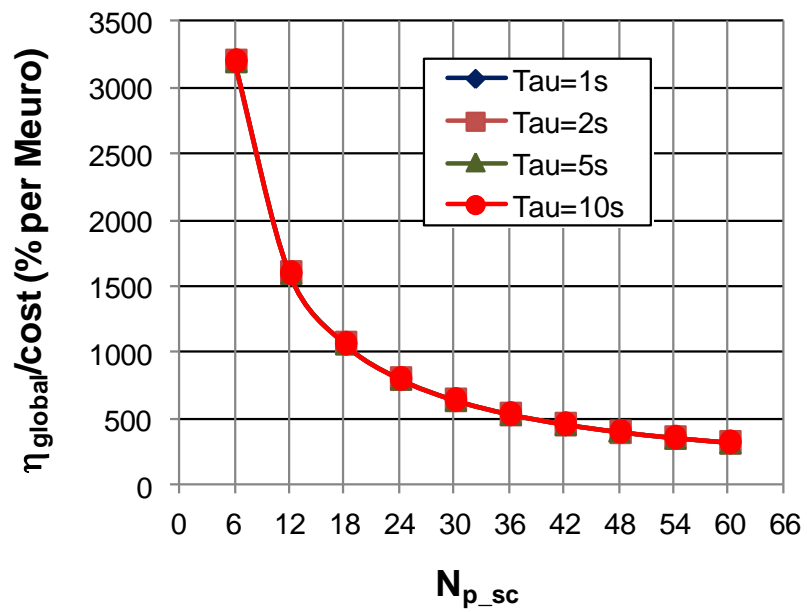

(b)

Fig. 18. Energy efficiency versus $T_{a u}$ and $N_{p_{-} s c}$

\section{Elimination rate of transient power}

A mechanistic analysis of lead acid battery shows that operation under high-rate discharge is the key factor responsible for the build-up of the lead sulfate layer, mainly at the surfaces of the negative plate, 
which leads to the battery failure [40], [41].

We consider that for the lead acid batteries used in the UPS, the high currents needed during fast changing load power can be supplied/absorbed by the SC's, potentially increasing the battery lifetime. The most important parameter is then the rate of the transient power applied to the battery that can be eliminated.

Therefore, the stopping time of supercapacitors is the best indicator of the elimination rate $\left(\tau_{\text {elim }}\right)$ of the power peaks required by the load. For example, if the SC's voltage reaches the minimum value of $150 \mathrm{~V}$ at time $300 \mathrm{~s}$, for the total backup time $(T=600 \mathrm{~s}), 50 \%$ of the power surges applied to the battery are eliminated.

We define the peak power elimination rate $\left(\tau_{\text {elim }}\right)$ by:

$\tau_{\text {elim }}(\%)=\frac{T_{\text {stop }}}{T} \times 100$

where:

- $T_{\text {stop }}$ is the final time at which the SC's pack reaches its minimum voltage,

- $T$ is the duration of the autonomous running equal to $10 \mathrm{~min}$.

As shown in Fig 19 (a), for a given parallel branches $N_{p_{-} s c}$, the elimination rate increases according to the filter constant $T_{a u}$. In fact, supercapacitors energy is switched and supplied by small parts. So, the SC's overcome greater number of peak power during the backup time. By dividing $\tau_{\text {elim }}$ by the SC's cost, we observe that the cost efficiency decreases for increasing $N_{p_{-} s c}$ (cf. Fig 19 (b)).

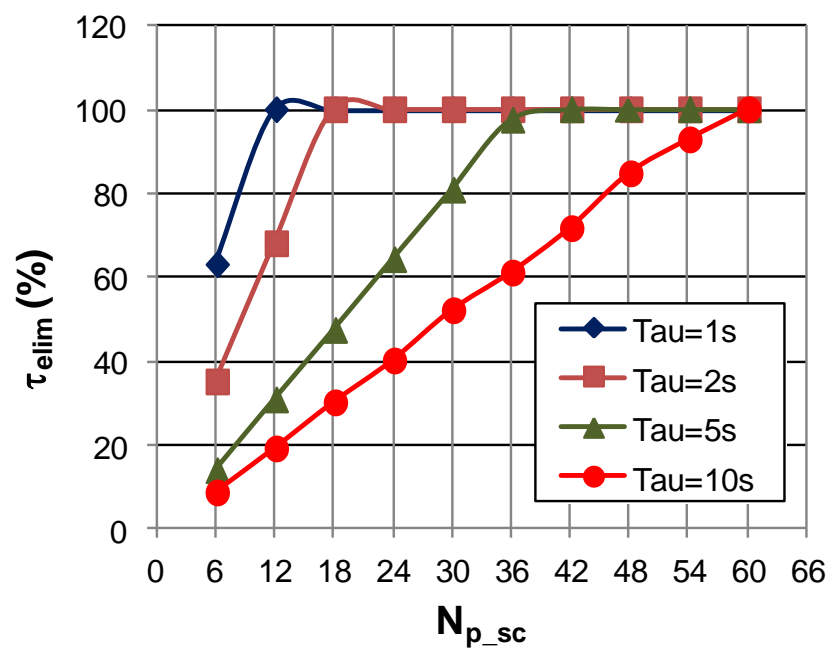

(a) 


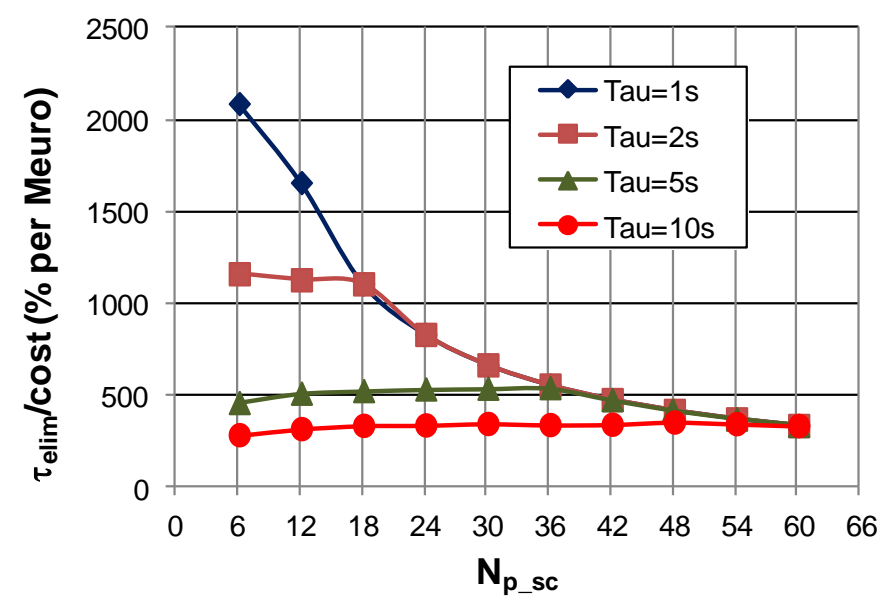

(b)

Fig. 19. Elimination rate of peak power versus $T_{a u}$ and $N_{p_{-} s c}$

In conclusion, by comparing the evolution of all these indicators, we notice a trade-off between the peak power elimination rate and the other performance indicators. In fact, unlike the RMS current-gain, the gain in battery energy losses and the global efficiency, $\tau_{\text {elim }}$ increases for decreasing filter constant for a given number of parallel branches.

However, the evolution of the performance parameters is in good concordance while divided by the cost of the SC's pack. The maximum point is obtained for $T_{a u}=1 \mathrm{~s}$ and $N_{p_{-} s c}=6$.

If we look at figures 16 (b), 17 (b) and 18 (b) showing the first three parameters $G_{-} I_{R M S}, W_{\text {losses }}$ and $\eta_{\text {global }}$ returned to the cost, we notice that for $T_{a u}=1 \mathrm{~s}$ and $T_{a u}=2 \mathrm{~s}$, and for $N_{p_{-} s c}=8$, the system performance are almost equal.

On the other side, taking $\tau_{\text {elim }}$ as the primary basic indicator, we have a clear advantage for $T_{a u}=1 \mathrm{~s}$. In fact, we show in the next paragraph that by planning SC's recharge through the battery, $T_{a u}=2 \mathrm{~s}$ becomes better than $T_{a u}=1 \mathrm{~s}$ for $N_{p_{-} s c}=8$ since $100 \%$ of the power inrushes are eliminated and the three other performance parameters are improved.

\section{B. Combination with $S C$ 's recharging}

In this section, the influence of the SC's recharging via the battery on the performance parameters is analyzed. The system is designed to extract from the battery a power used simultaneously to supply the load and to recharge the SC's pack whenever the load power $P_{l o a d}$ drops below a power limit denoted $P_{L m}$. The power load limit is set to $P_{L m}=80 \mathrm{~kW}$ and the power supplied by the battery is fixed at two levels.

A first recharge type consists in delivering $80 \mathrm{~kW}$ by the battery split between the load and the SC's $\left(I_{\text {bat_charge }}=200 \mathrm{~A}\right.$ at $\left.V_{D C}=400 \mathrm{~V}\right)$. In the second recharge type, the battery supplies $160 \mathrm{~kW}\left(I_{\text {bat_charge }}=\right.$ $400 \mathrm{~A}$ at $\left.V_{D C}=400 \mathrm{~V}\right)$.

It should be noted that the elimination rate as defined in Eq. (19) is minimally affected by the recharge of the SC's via the battery, since only rising power demand applied to the battery is considered.

We set the filter constant at $T_{a u}=2 \mathrm{~s}$ and we planned SC's recharge through the battery in order to inspect if the performance indicators can exceed those obtained for $T_{a u}=1 \mathrm{~s}$.

In Fig. 20 (a), (b), (c), (d), (e), (f), (g) and (h), we show the results of this investigation for $T_{a u}=2 \mathrm{~s}$ and $N_{p_{-} s c}$ between 6 and 15 branches. 


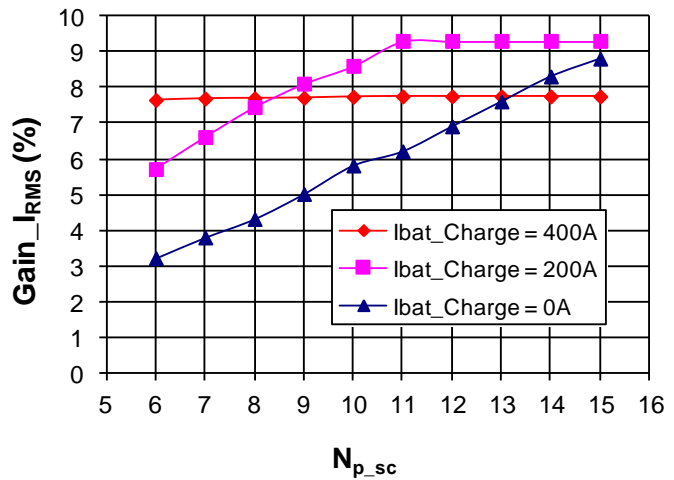

(a)

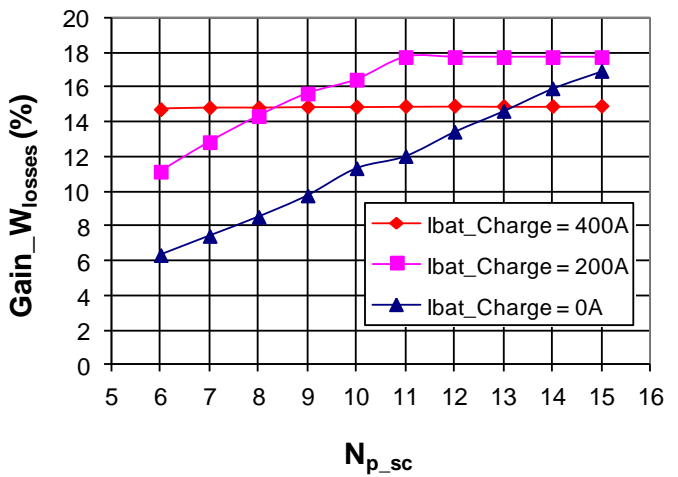

(c)

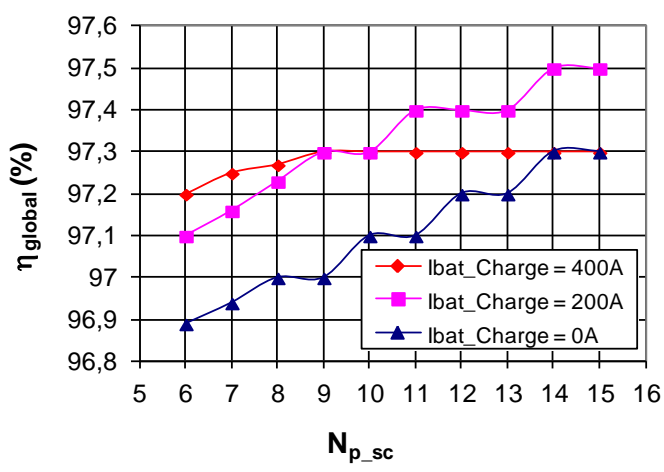

(e)

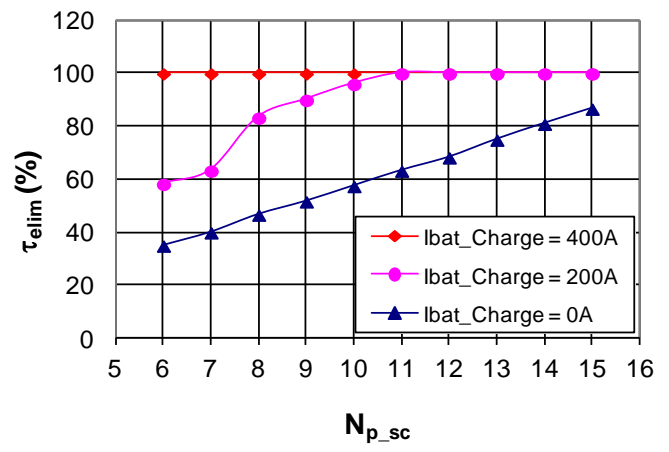

$(\mathrm{g})$

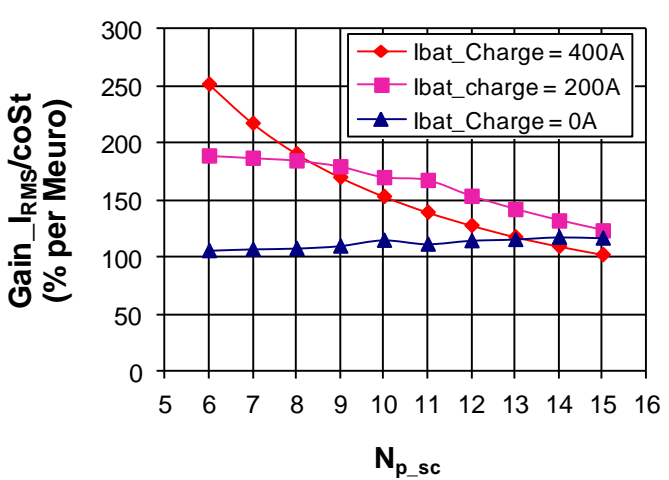

(b)

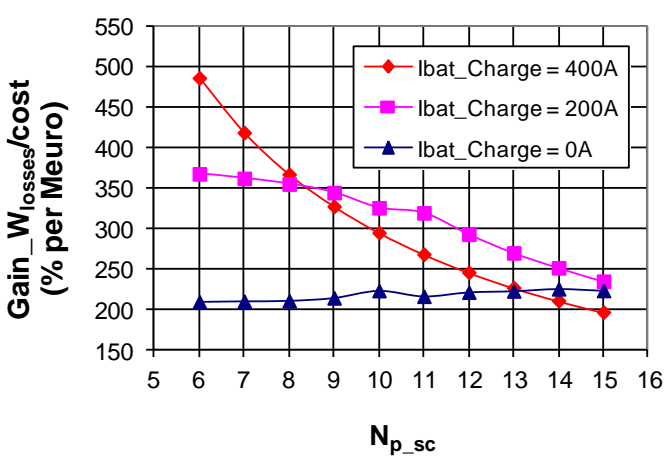

(d)

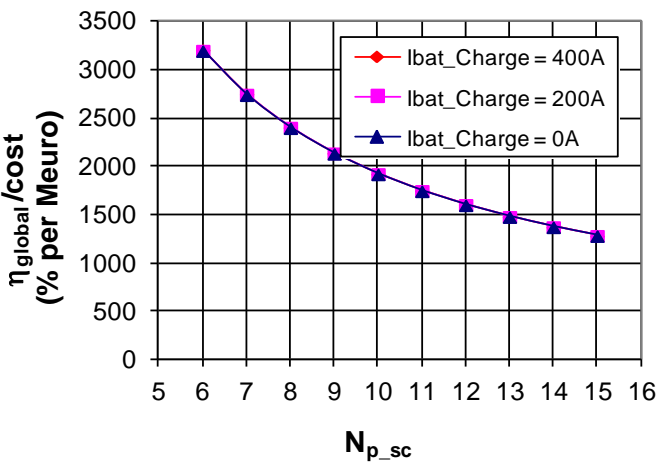

(f)

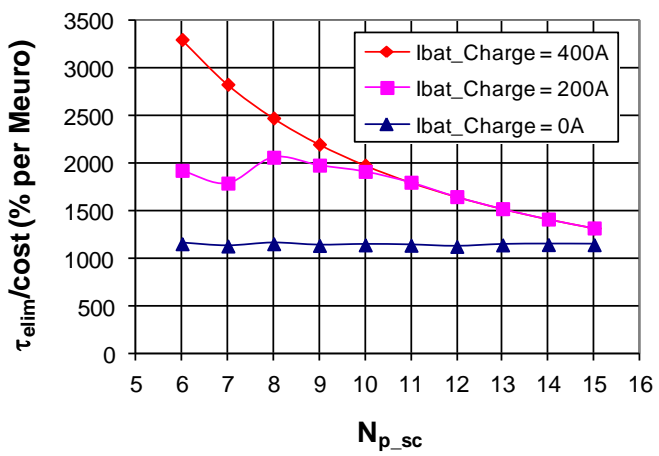

(h)

Fig. 20. System performances with SC's recharge through the battery 
We notice a clear improvement of all performance parameters for increasing $I_{\text {bat_charge }}$. This improvement is limited for $N_{p_{-} s c}$ between 6 and 8 branches and more noticeable for $I_{\text {bat_charge }}=400 \mathrm{~A}$.

The best configuration is then explored. It consists in finding a compromise between:

- Minimum of parallel branches for cost considerations,

- Maximum constant filter $T_{a u}$ for a better damping of power surges inflicted to the battery,

- Maximum gain in battery power losses,

- Maximum elimination rate of peak power.

We consider that the last criterion consisting in the potential gain in peak power is the most important one since it traduces peak stresses relief on battery and therefore the positive influence on the system performance [3], [42], [43].

We demonstrate in Fig. 21 that SC's recharge via the battery for $I_{b a t \_c h a r g e}=400 \mathrm{~A}$ and $N_{p_{-} s c}=8$ makes the system performances better for $T_{a u}=2 \mathrm{~s}$ than for $T_{a u}=1 \mathrm{~s}$. Moreover, $T_{a u}=2 \mathrm{~s}$ leads to better smoothing of the power extracted from the battery and implies better stresses reduction. The total cost of the SC's pack is then about $40 \mathrm{k} €$.

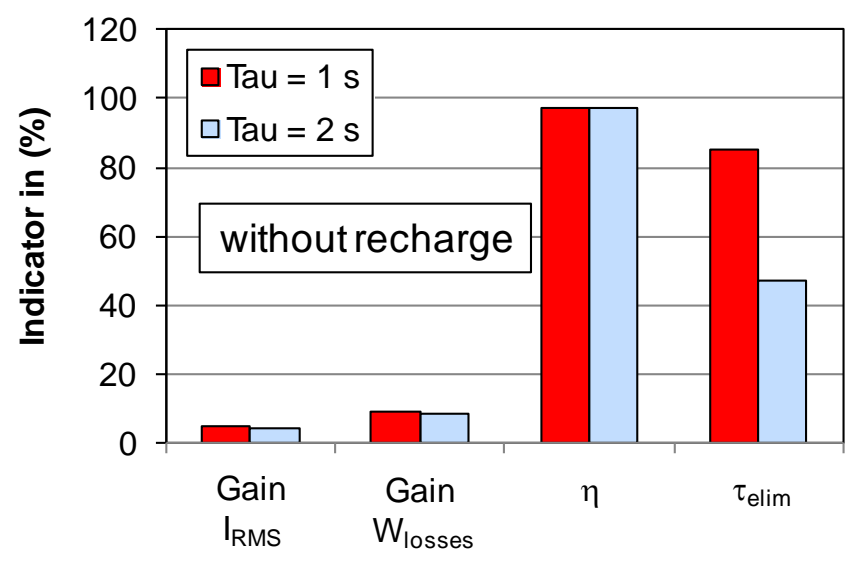

(a)

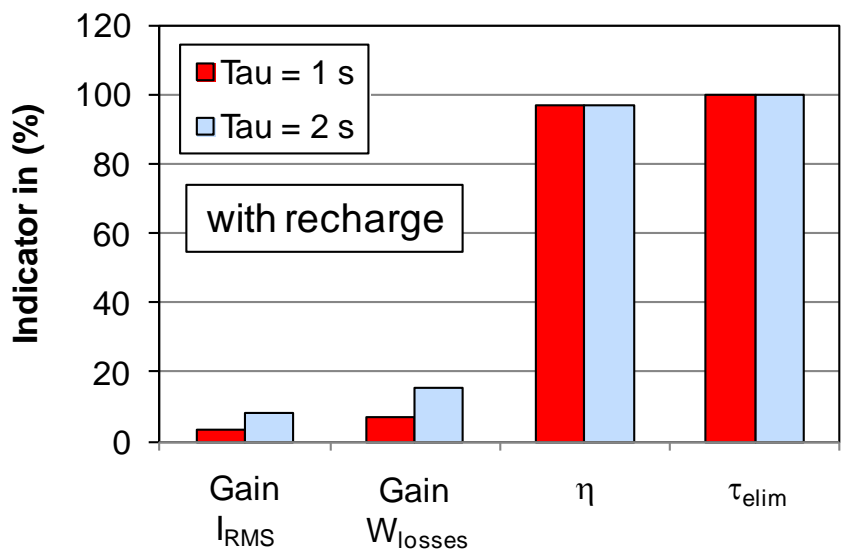

(b)

Fig. 21. Comparison between system performances for $T_{\mathrm{au}}=1 \mathrm{~s}$ and $T_{\mathrm{au}}=2 \mathrm{~s}\left(N_{\mathrm{p} \_\mathrm{sc}}=8\right)$

Fig. 22 shows the $P_{l o a d}, P_{b a t}$ and $P_{s c}$ profiles at the end of the backup time of $600 \mathrm{~s}$ for the optimal combination $\left(T_{a u}=2 \mathrm{~s}, N_{p_{-} s c}=8\right.$ and $\left.I_{\text {bat_charge }}=400 \mathrm{~A}\right)$. We notice that the SC's overcome all the peak power during $T=10 \mathrm{~min}$. thanks to the recharging operation through the battery. 


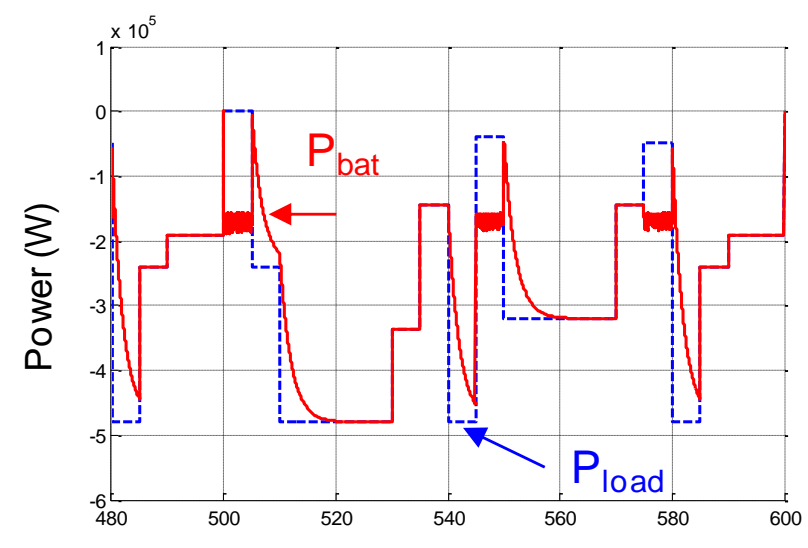

Time (s)

(a) $P_{\text {load }}$ and $P_{\text {bat }}$

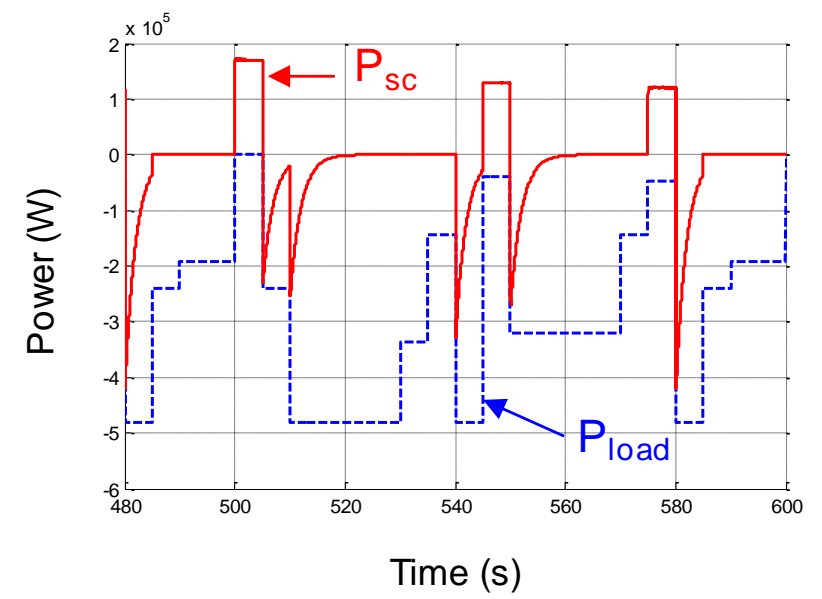

(b) $P_{\text {load }}$ and $P_{s c}$

Fig. 22. Power waveforms with intermediary SC's recharging

\section{SimUlation OF THE GLOBAL SYSTEM}

The system controlling the combination between the SC's and the battery in the $500 \mathrm{kVA}$ rated UPS is designed so that the SC's supply the full load power during short failures of the power source lasting up 10 seconds. Furthermore, the reappearing intermittent grid permits to recharge the SC's between successive outages. The SC's pack is then ready to supply the transient power load during the backup operation in order to reduce the battery stresses.

Fig. 23 illustrates the power waveforms of $P_{l o a d}, P_{b a t}$ and $P_{s c}$ for the UPS operation during three 10 seconds brownouts and for the optimal combination previously found. At time $t=80 \mathrm{~s}$, the system is switched to the 10 minutes autonomous operation. The full power is supplied by the SC's during the first intermittent functioning with fast charging through the power source. On the other side, during the backup time, only power impulses are covered by the SC's which are recharged through the battery. 


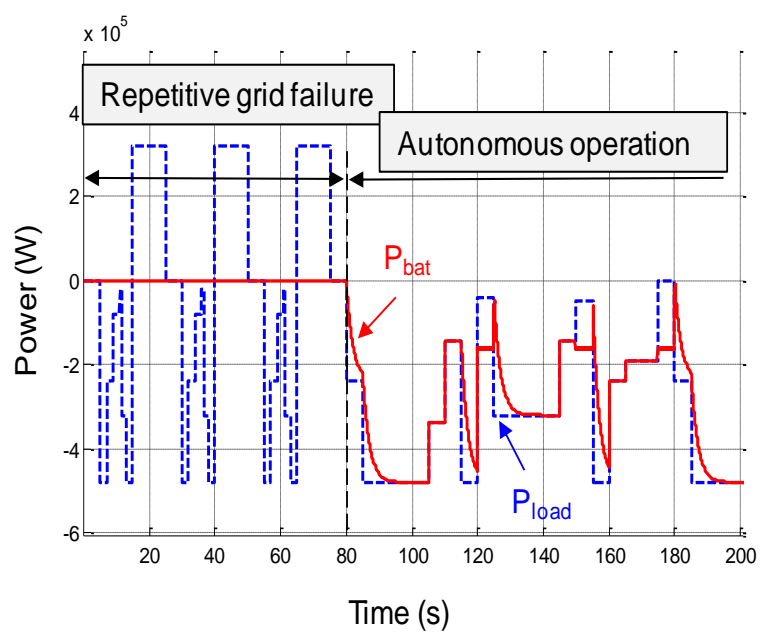

(a) $P_{\text {load }}$ and $P_{\text {bat }}$

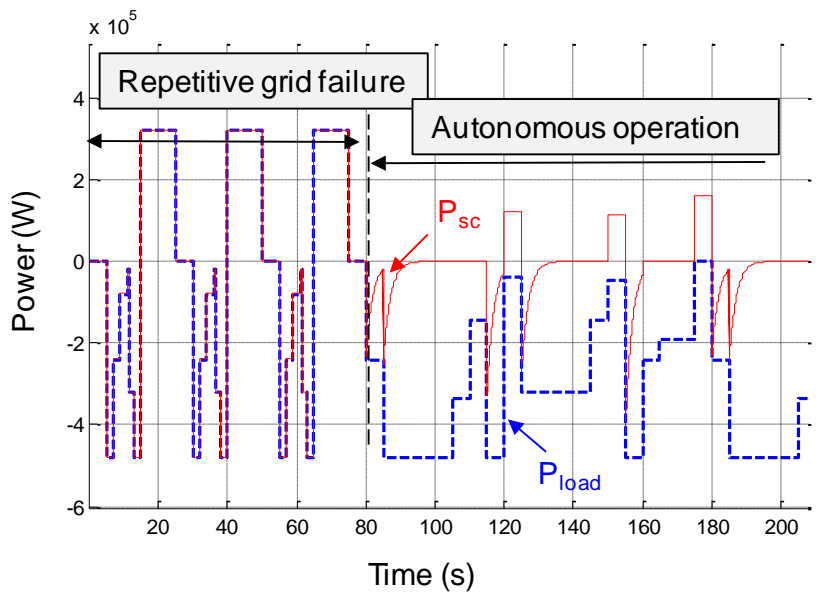

(b) $P_{\text {load }}$ and $P_{s c}$

Fig. 23. Power waveforms for successive brownout and autonomous operation

In Fig. 24 we represent the evolution of the battery voltage $U_{b a t}$ and the SC's voltage $U_{s c}$ during the two operation modes. We notice that thanks to capability of fast recharging of the SC's, their energy can be extracted then restituted in few seconds. Therefore, SC's the voltage $U_{s c}$ is maintained in the range of $[300 \mathrm{~V}-150 \mathrm{~V}]$ till the end of the backup time.

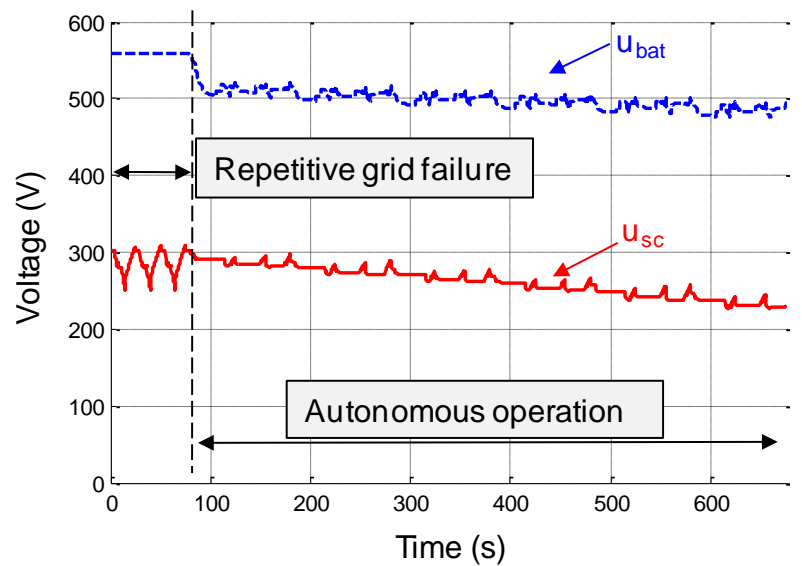

Fig. 24. Voltage waveforms for successive brownout and autonomous operation 


\section{CONCLUSION}

In this paper, the design of a control system which optimizes the battery-supercapacitors combination in a $500 \mathrm{kVA}$ rated UPS has been presented. The advantage of having a hybrid energy source for the UPS has been shown. The importance of supercapacitors in peak power smoothing has been elaborated on. The SC's pack and the battery are modeled using Matlab/Simulink software and then validated. The reduction in battery stresses has been discussed. The supercapacitors overcome the power surges and reduce high power demands away from the battery during the backup time. They also ensure the whole load power during outages lasting less than $10 \mathrm{~s}$.

The study of some performance parameters with respect to the cost of the SC's pack has also been presented and an optimal configuration has been found for a filter constant $T_{a u}=2 \mathrm{~s}$, a number of SC's parallel branches $N_{p_{-} s c}=8$ and battery recharge current $I_{\text {bat_charge }}=400 \mathrm{~A}$. The cost of this system is higher today than pure battery system however it should be pointed out that supercapacitors undergo intensive development and become more and more available in small-size and low price.

At the current state, the SC's pack cost is almost triple of the battery pack cost. The system we conceived would be efficient if the battery life time is enhanced at least 4 times. We are undertaking accelerated tests on lead acid batteries to observe the effect of pulsed loads and smoothed loads on battery wear-out process and reliability.

Some extensions of this work are undertaken and experimental bench has been set up to carry accelerated tests on lead acid batteries. We aim to observe the effect of pulsed loads and smoothed loads on battery wear-out process and reliability in order to quantify the efficiency of the designed system.

\section{ACKNOWLEDGMENTS}

The authors would like to thank APC by Schneider Electric, Grenoble, France, for its technical assistance.

\section{REFERENCES}

[1] Z. Chlodnicki, W. Koczara, and N. Al-Khayat, "Hybrid UPS Based on Supercapacitor Energy Storage and Adjustable Speed Generator," Electrical Power Quality and Utilisatio, Journal, vol. XIV, no. 1, 2008.

[2] A. M. Van Voorden, L. M. R Elizondo, G. C. Paap, J. Verboomen, and L. Van der Sluis, "The Application of Super Capacitors to relieve Battery-storage systems in Autonomous Renewable Energy Systems," IEEE Power Tech, Lausanne, 1-5 July 2007, pp. $479-484$.

[3] R. A. Dougal, S. Liu, and R. E. White, "Power and Life Extension of Battery-Ultracapacitor Hybrids," IEEE Transactions on Components and Packaging, vol. 25, no. 1, March 2002.

[4] Alfred Rufer and Philippe Barrade, "A Supercapacitor-Based Energy-Storage System for Elevators With Soft Commutated Interface," IEEE Transactions on Industry Applications, vol. 38, no. 5, Sept./Oct. 2002.

[5] S. Mallika and R. S. Kuma, "Reniew on Ultracapacitor-Battery Interface for Energy Management System," International Journal of Engineering and Technology, vol. 3 (1), 2011, pp. 37-43.

[6] F. Rafik, H. Gualous, R. Gallay, A. Crausaz, and A. Berthon, "Frequency, thermal and voltage supercapacitor characterization and modeling," Journal of Power Sources, vol. 165, pp. 928-934, 2007.

[7] C. M. Krishna, "Managing Battery and Supercapacitor Resources for Real-Time Sporadic Workloads," IEEE Embedded Systems Letters, vol. 3, no. 1, March 2011.

[8] F. Belhachemi, S. Rael, and B. Davat, "A physical based model of power electric double-layer supercapacitors," Proc. of IEEE Industry Appl. Conf., pp. 2069-3076, 2000.

[9] M. B. Camara, B. Dakyo, and H. Gualous, "Polynomial Control Method of DC/DC Converters for DCBus Voltage and Currents Management-Battery and Supercapacitors," IEEE Transactions on Power Electronics, vol.27, no. 3, pp.1455-1467, March 2012. 
[10]A. Haddoun, M. El Hachemi Benbouzid, D. Diallo, R. Abdessemed, J. Ghouili, and K. Srairi, "Modeling, analysis, and neural network control of an EV electrical differential," IEEE Trans. Ind. Electron., vol. 55, no. 6, pp. 2286-2294, Jun. 2008.

[11]A. F. Burke, "Batteries and Ultracapacitors for Electric, Hybrid, and Fuel Cell Vehicles," Proceedings of the IEEE, vol. 95 Issue 4, pp. 806-820, April 2007.

[12]M. B. Camara, H. Gualous, F. Gustin, and A. Berthon, "Design and New Control of DC/DC Converters to Share Energy Between Supercapacitors and Batteries in Hybrid Vehicles," IEEE Transactions on Vehicular Technology, vol. 57, no. 5, September 2008, pp. 2731-2735.

[13]L. Gao, R. A. Dougal, and Shengyi Liu, "Power Enhancement of an Actively Controlled Battery/Ultracapacitor Hybrid," IEEE Trans. on Power Electronics, vol. 20, no. 1, pp. 236-243 January 2005.

[14]P. Thounthong, S. Raël, and B. Davat, "Energy management of fuel cell/battery/supercapacitor hybrid power source for vehicle applications," Journal of Power Sources, vol. 193, pp. 376-385, 2009.

[15]E. Schaltz, A. Khaligh, and P. O. Rasmussen (2008), "Investigation of Battery/Ultracapacitor Energy Storage Rating for a Fuel Cell Hybrid Electric Vehicle", IEEE Vehicle Power and Propulsion Conference (VPPC), September 3-5, 2008, Harbin, China.

[16]A. Khaligh and Z. Li, "Battery, ultracapacitor, fuel cell, and hybrid energy storage systems for electric, hybrid electric, fuel cell, and plug-in hybrid electric vehicles: State of the art," IEEE Trans. Vehicular Technol., vol. 59, no. 6, pp. 2806-2814, Jul. 2010.

[17]Z. Zhang, Z. Ouyang, O. C. Thomsen, and M. A. E. Andersen, "Analysis and Design of a Bidirectional Isolated DC-DC Converter for Fuel Cells and Supercapacitors Hybrid System," IEEE Trans. on Power Electronics, vol. 27, no. 2, pp. 848-859, February 2012.

[18]J. Jia, Y. Wang, S. Li, and G. Wang, "A dynamic discharge structure for ultracapacitor application in the fuel cell UPS," 10th International Conference on Control, Automation, Robotics and Vision, ICARCV 2008, pp. 2102-2107.

[19]M. V. Chellappan, M. H. Todorovic, and P. N. Enjeti, "Fuel Cell Based Battery-Less UPS System," Industry Applications Society Annual Meeting, 2008. IAS'08, pp. 1-8.

[20]S. Li, X. Feng, J. B Jia, and K. Li, "A three-switch structure for PEMFC and ultracapacitor hybrid in backup power," IEEE 6th International Power Electronics and Motion Control Conference, IPEMC'09, pp. 2309-2312.

[21]F. Esposito, V. Isastia, and S. Meo, "PSO Based Energy Management Strategy for Pure Electric Vehicles with Dual Energy Storage Systems," International Review of Electrical Engineering (IREE), vol. 5. no. 5, October 2010, Part A, pp. 1862-1871.

[22]T. Peppel, G. Sartorelli, and A. Schneuwly, "Elimination of high power delivery rates by energy storage in supercapacitors," European Conference on Power Electronics and Applications, 2005.

[23]P. Mars, "A Survey of Supercapacitors, Their Applications, Power Design with Supercapacitors, and Future Directions," IEEE Technology Time Machine Symposium on Technologies Beyond 2020, 1-3 June 2011, pp. 1-2.

[24]A. Stepanov, I. Galkin, L. Bisenieks, "Implementation of supercapacitors in uninterruptible power supplies," European Conference on Power Electronics and Applications, Aalborg, 2-5 Sept. 2007.

[25]J. M. Gurrero, L. G. De Vicuna, and J. Uceda, "Uninterruptible power supply systems provide protection," IEEE Industrial Electronics Magazine, vol. 1, Issue 1, pp. 28-38, 2007.

[26]H. Markiewicz and A. Klajn, "Voltage Disturbances, Standard EN 50160 - Voltage Characteristics in Public Distribution Systems," Leonardo Power Quality Initiative (LPQI), www.lpqi.org, July 2004.

[27]W. Choi, J. W. Howze, and P. Enjeti, "Fuel-cell powered uninterruptible power supply systems: Design considerations," Journal of Power Sources, vol. 157, no. 1, pp. 311-317, 2006.

[28]L. Zubieta and R. Bonert, "Characterization of double-layer capacitors for power electronics applications," IEEE Transactions on Industry Applications, vol. 36, no. 1, Jan/Feb 2000. 
[29]H. Gualous, D. Bouquain, A. Bertbon, and J.M. Kauffinann, "Experimental study of supercapacitor serial resistance and capacitance variations with temperature," Journal of Power Sources, vol. 123, (2003), pp. 86-93.

[30]D. Rakhmatov, S. Vrudhula, and D. A. Wallach, "A model for battery lifetime analysis for organizing applications on a pocket computer," IEEE Trans. Very Large Scale Integr. (VLSI) Syst., vol. 11, no. 6, pp. 1019-1030, June 2003.

[31]B. S. Bhangu, P. Bentley, D.A. Stone, and C.M. Bingham, "Nonlinear Observers for Predicting Stateof-Charge and State-of-Health of Lead-Acid Batteries for Hybrid-Electric Vehicles," IEEE Trans. on Vehicular Technology, vol. 54, no. 3, May 2005.

[32]J. Chiasson and B. Vairamohan, "Estimating the State of Charge of a Battery," IEEE Trans. on Control System Technology, vol. 13, no. 3, May 2005.

[33]O. Tremblay and L. A. Dessaint, "Experimental Validation of a Battery Dynamic Model for EV Applications," World Electric Vehicle Journal, vol. 3, 2009.

[34]C. M. Shepherd, "Design of Primary and Secondary Cells - Part 2. An equation describing battery discharge," Journal of Electrochemical Society, vol. 112, pp. 657-664, Jul. 1965.

[35]A. Lahyani, P. Venet and A. Troudi, "Design of Power Sharing System Between Supercapacitors and Battery in an Uninterruptible Power Supply (UPS)," IEEE $33^{\text {rd }}$ International Telecommunications Energy Conference, INTELEC'11, Amsterdam, The Netherlands 9-13 Oct. 2011.

[36]J. R. Miller, "Battery-capacitor power source for digital communication applications: Simulations using advanced electrochemical capacitors," Proc. Electrochem. Soc. Conf., vol. 95-29, Oct. 1995, pp. 246-254.

[37]L. P. Jarvis, T. B. Atwater, and P. J. Cygan, "Fuel cell/electrochemical capacitor hybrid for intermittent high power applications," J. Power Sources, vol. 79, pp. 60-63, 1999.

[38]L. P. Jarvis, T. B. Atwater, and P. J. Cygan, "Hybrid power sources for land warrior scenario," IEEE Aerosp. Electron. Syst. Mag., pp. 37-41, Sept. 2000.

[39]T. Andersson, J. Groot, H. Berg, J. Lindström, and T. Thiringer, "Alternative Energy Storage System for Hybrid Electric," Vehicles 4th Nordic Workshop on Power and Industrial Electronics, Trondheim 14-16 June 2004.

[40]D. U. Sauer and H. Wenz, "Comparison of different approaches for lifetime prediction of electrochemical - using lead acid batteries as example," Journal of Power Sources, vol. 176, no. 2, pp. 534-546, February 2008.

[41]L. Lam, N. Haigh, C. Phyland, and A. Urban (2004), "Failure mode of valve-regulated lead-acid batteries under high-rate partial-state-of-charge operation," Journal of Power Sources, vol. 133, pp. 126-134, January 2004.

[42]D. Casadei, G. Grandi, and C. Rossi, "A supercapacitor-based power conditioning system for power quality improvement and uninterruptible power supply," Proceedings of the 2002 IEEE International Symposium on Industrial Electronics, vol. 4, pp. 1247-1252, 2002.

[43]A. Schneuwly, G. Sartorelli, J. Auer, and B. Maher, "Ultracapacitors revolutionize the power electronic world," $10^{\text {th }}$ European Power Electronics Conference, EPE'2003, N¹162, Toulouse, France, Sept. 2003. 